\title{
3 Research Square

\section{The Synergistic Effect of The Preceding Winter Northern Hemisphere Annular Mode and Spring Tropical North Atlantic SST On Spring Extreme Cold Events in The Mid-high Latitudes of East Asia}

\section{Hao Wang}

Ocean University of China

Fei Zheng

Sun Yat-Sen University

Yina Diao

Ocean University of China

Jianping Li ( $\sim$ ljp@ouc.edu.cn )

Ocean University of China https://orcid.org/0000-0003-0625-1575

\section{Xinxin Tang}

Ocean University of China

\section{Yue Sun}

Ocean University of China

\section{Fei Li}

Ocean University of China

\section{Yazhou Zhang}

Ocean University of China

\section{Research Article}

Keywords: Extreme cold events, East Asia, Northern Hemisphere Annular Mode, North Atlantic, Synergistic effect

Posted Date: November 19th, 2021

DOI: https://doi.org/10.21203/rs.3.rs-1089661/v1

License: (9) (1) This work is licensed under a Creative Commons Attribution 4.0 International License.

Read Full License 
Version of Record: A version of this preprint was published at Climate Dynamics on April 18th, 2022. See the published version at https://doi.org/10.1007/s00382-022-06237-w. 
The synergistic effect of the preceding winter Northern Hemisphere

\section{Annular Mode and spring Tropical North Atlantic SST on spring} extreme cold events in the mid-high latitudes of East Asia

Hao Wang ${ }^{1}$, Fei Zheng ${ }^{2,3^{*}}$, Yina Diao ${ }^{1}$, Jianping $\mathrm{Li}^{1,4^{*}}$, Xinxin Tang $^{1}$, Yue Sun $^{1}$, Fei $\mathrm{Li}^{1}$, and Yazhou Zhang ${ }^{1}$

${ }^{I}$ Frontiers Science Center for Deep Ocean Multispheres and Earth System-Key Laboratory of Physical Oceanography-Institute for Advanced Ocean Studies-Academy of the Future Ocean, Ocean University of China, Qingdao 266100, China.

${ }^{2}$ School of Atmospheric Sciences, Key Laboratory of Tropical Atmosphere-Ocean System, Ministry of Education, Sun Yat-sen University, Zhuhai 519082, China

${ }^{3}$ Southern Marine Science and Engineering Guangdong Laboratory, Zhuhai 519082, China.

${ }^{4}$ Laboratory for Ocean Dynamics and Climate, Pilot Qingdao National Laboratory for Marine Science and Technology, Qingdao 266237, China.

* Corresponding author address:

Prof. Fei Zheng

E-mail: zhengf35@mail.sysu.edu.cn

Prof. Jianping Li

E-mail: ljp@ouc.edu.cn 


\section{Abstract}

In this paper, the synergistic effect of the preceding winter positive Northern Hemisphere annular mode (pNAM) and spring negative tropical North Atlantic (nTNA) sea surface temperature anomaly (SSTA) on spring extreme cold events in the mid-high latitudes of East Asia (MHEA) is investigated. The results show that the co-occurrence of the two factors is unfavorable for extreme cold events during spring in the MHEA via the snow cover and atmospheric bridges. Over the Atlantic, the spring nTNA SSTA can lead to an atmospheric response that is similar to the North Atlantic Oscillation (NAO), which enhances the persistence of the pNAM and in turn amplifies the negative spring Eurasian snow cover extent (EASCE) anomaly caused by the preceding winter pNAM. Meanwhile, the spring EASCE is closely related to the spring MHEA anomalous anticyclone. In addition to storing its signal in the spring EASCE, the spring nTNA SSTA can also lead to the spring MHEA anomalous anticyclone via the eastward Rossby wave train. The evidence shows that the Rossby wave energy can propagate eastward to the MHEA as a result of the enhanced negative spring EASCE anomaly and Rossby wave induced by the spring nTNA SSTA, and the two factors have an obvious synergistic effect on the spring MHEA anomalous anticyclone. This anomalous MHEA anticyclone becomes a barrier that can hinder the intrusion of cold air from the polar region and can increase the thickness of the atmospheric layer. The anomalous sinking motion of the spring MHEA anomalous anticyclone can also lead to an increase in net radiation received at the surface and increase the air temperature through the vertical motion of air. The southerly wind over the west side of the spring MHEA anomalous anticyclone leads to horizontal warm advection. All of the above processes favor an increase in air temperature and dampen extreme cold events, implying the synergistic effect of the preceding winter pNAM and spring nTNA SSTA on spring extreme cold events in the MHEA. 
60 Key Words: Extreme cold events; East Asia; Northern Hemisphere Annular Mode; North

61 Atlantic; Synergistic effect 


\section{Introduction}

East Asia is among the global regions that are most sensitive to extreme temperatures because it experiences evident climatic fluctuations and has a large population (Xin et al. 2013). The mid-high latitudes of East Asia (MHEA) are mainly semi-arid, and the most important climatic characteristic in this region is its temperature fluctuations, and semi-arid regions are always vulnerable to climate change (Huang et al. 2015). The Rossby wave train brings cold advection downstream and readily causes cold-air outbreaks into East Asia (Joung and Hitchman 1982; Cheung et al. 2012; Park et al. 2014). Extreme cold events occur frequently in this area and, with the accompanying snowstorms and cold rains, they often cause heavy losses to arable and livestock farming, which are the main industries in this region (Chen 2002; Chen et al. 2004; Jeong et al. 2008; Park et al. 2010). Therefore, investigating the interannual variability of extreme cold events in the MHEA and the associated mechanisms is of great importance and may help people better understand and predict these extreme climatic events and reduce the impacts associated with them.

The large-scale atmospheric circulation in the extratropical Northern Hemisphere is dominated mainly by the Northern Hemisphere Annular Mode (NAM), also known as the Arctic Oscillation (AO; Thompson and Wallace 1998, 2000; Li and Wang 2003). Several studies have demonstrated that the NAM deforms the Siberian high and then influences the outbreak of cold waves that can further impact the occurrence of East Asian snowstorms (Li and Wu 2012; Screen and Simmonds 2013). The coupled landatmosphere bridge plays an important part in linking the mid-latitude air temperature with the NAM (Li et al. 2019a). As the Eurasian snow cover anomalies are strongly associated with the NAM, and can persist for a long time, the Eurasian snow cover can store the signal of the NAM and then release it into the atmosphere (Bamzai 2003; 
Robock et al. 2003; Saito and Cohen 2003; Saito et al. 2004). Yin et al. (2013) showed that the preceding winter NAM is negatively correlated with spring extreme cold events in northeast China via the coupled land-atmosphere bridge ( $\mathrm{Li}$ et al. 2019a). The NAM is also related to the Siberian high, and the strong westerlies when the positive phase of the NAM develops are a major factor in the weakening of the Siberian high, which can have further impacts on the East Asian climate (Gong and Ho 2002).

In addition to the NAM, are there other factors that influence the MHEA? Previous studies have found that the North Atlantic can modulate the surface air temperature (SAT) over East Asia through the easterly propagating Rossby wave (Wu et al. 2016; Lin et al. 2016). Monerie et al. (2018) highlighted the role of the Atlantic sea surface temperature anomaly (SSTA) in predicting the SAT anomaly in the MHEA. Chen et al. (2016) showed that the North Atlantic SST tripole mode is important for the tripole SAT anomalies pattern over the Eurasian continent in spring. Qiao and Feng (2016) found that the North Atlantic SSTA can influence the East Asia trough, which is important in modulating the SAT in the MHEA through the Rossby wave train.

The NAM and Atlantic SSTA can both influence climate variability in the MHEA. However, the synergistic effect of these two factors on influencing the interannual variability of extreme temperatures in East Asia is unknown, and the associated internal mechanism remains unclear. Li et al. (2019a) put forward a new method to examine the synergistic effect of these two factors, and this method has been applied in subsequent studies. For example, Zheng et al. (2021) found that the 2020/21 winter extreme cold event in China was related to the synergistic effect of the 2020/21 La Niña in winter and the warm Arctic. An et al. (2021) revealed the impact of Pacific and Atlantic SSTAs on the SAT anomaly over the Mongolian Plateau and showed that these two factors rely mainly on changing the strength of the circumglobal teleconnection to exert their 
112 synergistic effect. Sun and Li (2021) found that wintertime precipitation over

113 southeastern China and the Kuroshio Current in the East China Sea, are significantly

114 enhanced by the synergistic effect of El Niño and the positive phase of the North Pacific

115 Oscillation.

116 The interannual variability of extreme temperatures in East Asia is of great

117 importance; however, it is rarely investigated. As the NAM in the preceding winter may

118 dampen spring extreme cold events in the MHEA (Yin et al. 2013), and the Atlantic

119 SSTA can also influence the air temperature in East Asia (Qiao and Feng 2016; Monerie

120 et al. 2018), we will focus in this paper on the synergistic effect of the preceding winter

121 positive NAM (pNAM) and the negative tropical North Atlantic (nTNA) SSTA in 122 spring.

123 The remainder of the paper is organized as follows. Section 2 describes the data

124 and methodology used in this study. Section 3 describes the synergistic effect of the

125 preceding winter pNAM and spring nTNA SSTA on spring extreme cold events and the

126 related atmospheric circulation characteristics in the MHEA, as well as the factors

127 influencing the variability of the spring extreme cold events. The mechanisms related

128 to the synergistic effect are presented in Section 4. A summary and discussion follow 129 in Section 5.

\section{2. Data and methods}

$131 \quad 2.1$ Data

132 The datasets used in this study are listed in Table 1. The SST data used here is

133 HadISST1 (version 1.1) provided by the Met Office Hadley Center (Rayner et al. 2003)

134 for the period between 1870 and March 2021 on a $1^{\circ}$ latitude $\times 1^{\circ}$ longitude grid. For

135 the extreme temperature indices, we use HadEX3 from the Met Office Hadley Center 
136 (Dunn et al. 2020) to provide the gridded data. The HadEX3 dataset is derived from a

137 number of stations, includes quality control checks, and provides reliable extreme

138 temperature indices. HadEX3 covers the period $1901-2018$ on a $1.25^{\circ}$ latitude $\times 1.875^{\circ}$

139 longitude mesh. We used the TNn, TXn, TN10p, and TX10p indices from the HadEX3

140 dataset, which represent the monthly lowest value of the daily minimum temperature,

141 the monthly lowest value of the daily maximum temperature, the percentage of time

142 when the daily minimum temperature is lower than the 10th percentile, and the

143 percentage of time when the daily maximum temperature is lower than the 10th

144 percentile, respectively. These extreme temperature indices can accurately describe the

145 intensity and frequency of extreme cold events (Dunn et al. 2020). We use the global

146 time series in the HadCRUT4 dataset (from 1850 to January 2021), obtained from the

147 Met Office Hadley Center (Morice et al. 2012), to remove the influence of global

148 warming. To investigate the variability of Eurasian snow cover, the monthly Eurasian

149 snow cover extent (EASCE) time series was obtained from the Global Snow Lab of

150 Rutgers University, which covers the period between 1966 and 2021 (Robinson et al.

151 2012). We used the National Centers for Environmental Prediction-National Center for

152 Atmospheric Research (NCEP-NCAR) reanalysis dataset for the geopotential height,

153 winds, vertical velocity (omega), air temperature, and sea level pressure (SLP) data

154 (Kalnay et al. 1996). The NCEP-NCAR reanalysis dataset covers the period from 1948

155 to May 2021 on a $2.5^{\circ}$ latitude $\times 2.5^{\circ}$ longitude grid.

156 As the HadEX3 dataset ends in 2018, and has some missing data over East Asia

157 before 1960, we use the period 1961-2018 for this study.

\subsection{Methods}

In this paper, we define winter as December-January-February and spring as 
March-April-May. For example, spring in 2010 covers the period March-May of 2010,

161 and the preceding winter covers December 2009 to February 2010.

We used the two-tailed Student's $t$ test to determine statistical significance. To

163 examine whether there is a synergistic effect from two forcing factors $F_{1}$ and $F_{2}$, we

164 follow the method put forward by Li et al. (2019a). This method can diagnose the joint

165 effects statistically and judge the existence of synergistic effect. Each of the forcing

166 factors can be divided into positive, negative, and neutral phases, and one phase is

167 chosen for each factor. Assuming we select the positive phase for each factor, the

168 condition for each factor can be presented as $F_{1}^{+}$and $F_{2}^{+} . F_{1}^{+} \oplus F_{2}^{+}$denotes the cases

169 when $F_{1}^{+}$and $F_{2}^{+}$both occur, and the related cases are termed as joint events $F_{1}^{+} \oplus F_{2}^{+}$.

$170 F_{1}^{+} \backslash F_{2}^{+}$indicates the cases when $F_{1}^{+}$occurs without $F_{2}^{+}$, and the related cases are

171 termed as single $F_{1}^{+}$events. In addition, $F_{2}^{+} \backslash F_{1}^{+}$denotes cases when $F_{2}^{+}$occurs

172 without $F_{1}^{+}$, and the related cases are termed as single $F_{2}^{+}$events. If we study the

173 response (say $T$ ) of y to $F_{1}^{+}$and $F_{2}^{+}$, we can compare the difference between the

174 composite amplifications of different events. If the $|T|$ of $F_{1}^{+} \oplus F_{2}^{+}$is greater than the

175 maximum of the $|T|$ of $F_{1}^{+} \backslash F_{2}^{+}$and $F_{2}^{+} \backslash F_{1}^{+}$, this indicates that there is a synergistic

176 effect from $F_{1}^{+}$and $F_{2}^{+}$. Conversely, if the $|T|$ of $F_{1}^{+} \oplus F_{2}^{+}$is less than the minimum

177 of the $|T|$ of $F_{1}^{+} \backslash F_{2}^{+}$and $F_{2}^{+} \backslash F_{1}^{+}$, this indicates there is an antagonistic effect from

$178 F_{1}^{+}$and $F_{2}^{+}$. Finally, if the $|T|$ of $F_{1}^{+} \oplus F_{2}^{+}$is between the $|T|$ of $F_{1}^{+} \backslash F_{2}^{+}$and $F_{2}^{+} \backslash F_{1}^{+}$,

179 this indicates that there is no combined effect from $F_{1}^{+}$and $F_{2}^{+}$. Therefore, using this

180 method, we can easily judge whether the two influencing factors can generate a

181 synergistic effect.

182 We also performed dynamical diagnosis by using the Rossby wave ray tracing 183 theory in a horizontally non-uniform basic flow (Li and Li 2012; Li et al. 2015, 2019b, 184 2021; Zhao et al. 2015, 2019), by means of which the trajectory of the stationary Rossby 
wave train is traced and the pathway of the impact of the TNA is characterized. As in

186 previous studies (Karoly 1983; Li and Nathan 1997; Li and Li 2012; Li et al. 2015;

187 Zhao et al. 2015, 2019), the dispersion relationship of the Rossby wave frequency and

188 wavenumber in a horizontally non-uniform flow can be written as:

$189 \omega$

$190=\bar{u}_{M} k+\bar{v}_{M} l$

$191+\frac{\bar{q}_{x} l-\bar{q}_{y} k}{k^{2}+l^{2}}$

192 where $\omega$ is the wave frequency; $k$ and $l$ are the zonal and meridional wavenumbers,

193 respectively; $\left(\bar{u}_{M}, \bar{v}_{M}\right)=(\bar{u}, \bar{v}) / \cos \varphi$ is the Mercator projection of zonal and

194 meridional winds; $\varphi$ is the latitude; $\bar{q}=\nabla_{M}^{2} \bar{\psi} / \cos ^{2} \varphi+f$ represents the absolute

195 vorticity of the background; and $\bar{q}_{x}$ and $\bar{q}_{y}$ are the zonal and meridional gradients of

$196 \bar{q}$. Let $K=\sqrt{k^{2}+l^{2}}$ represent the total wavenumber, and the zonal and meridional

197 components of the group velocity take the form:

$$
198 \quad \begin{aligned}
& u_{g}=\frac{\partial \omega}{\partial k} \\
& 199=\bar{u}_{M}+\frac{\left(k^{2}-l^{2}\right) \bar{q}_{y}-2 k l \bar{q}_{x}}{K^{4}} .
\end{aligned}
$$

$$
+\frac{\left(k^{2}-l^{2}\right) \bar{q}_{x}+2 k l \bar{q}_{y}}{K^{4}}
$$

As the background flow changes along the ray, the wavenumbers determined by the

203 kinematic wave theory (Whitham 1960) can be written as:

$$
\begin{gathered}
\frac{d_{g} k}{d t}=-\frac{\partial \omega}{\partial x}=-k \frac{\partial \bar{u}_{M}}{\partial x}-l \frac{\partial \bar{v}_{M}}{\partial x}-\frac{1}{K^{2}}\left(l \frac{\partial \bar{q}_{x}}{\partial x}-k \frac{\partial \bar{q}_{y}}{\partial x}\right) \\
\frac{d_{g} l}{d t}=-\frac{\partial \omega}{\partial y}=-k \frac{\partial \bar{u}_{M}}{\partial y}-l \frac{\partial \bar{v}_{M}}{\partial y}-\frac{1}{K^{2}}\left(l \frac{\partial \bar{q}_{x}}{\partial y}-k \frac{\partial \bar{q}_{y}}{\partial y}\right)
\end{gathered}
$$


where $\frac{d_{g}}{d t}=\frac{\partial}{\partial t}+\bar{u}_{g} \frac{\partial}{\partial x}+\bar{v}_{g} \frac{\partial}{\partial y}$ represents the material derivative moving with the 207 group velocity. According to Equation (3), the zonal and meridional wavenumbers 208 change along the wave ray, which differs from the classic theory (Hoskins and Karoly 209 1981). Equations (2) and (3) are termed the wave ray tracing equation set. Therefore, 210 after giving the initial position and zonal wavenumber $k$, the initial local meridional 211 wave number $l$ can be determined using Equation (1). Then, the wave ray tracing 212 equation set can be applied to obtaining the corresponding wave ray trajectory. For a 213 large-scale Rossby wave, the integration is terminated when the local meridional 214 wavelength is less than $1000 \mathrm{~km}$.

215 To investigate the propagation of a stationary Rossby wave, we also calculated the 216 wave activity flux (Takaya and Nakamura 2001). The horizontal wave activity flux is 217 calculated as follows:

$$
\frac{p \cos \varphi}{2|\overline{\mathrm{U}}|}\left(\begin{array}{c}
\frac{\bar{u}}{a^{2} \cos ^{2} \varphi}\left[\left(\frac{\partial \psi^{\prime}}{\partial \lambda}\right)^{2}-\psi^{\prime} \frac{\partial^{2} \psi^{\prime}}{\partial \lambda^{2}}\right]+\frac{\bar{v}}{a^{2} \cos \varphi}\left[\frac{\partial \psi^{\prime}}{\partial \lambda} \frac{\partial \psi^{\prime}}{\partial \varphi}-\psi^{\prime} \frac{\partial^{2} \psi^{\prime}}{\partial \lambda \partial \varphi}\right] \\
\frac{\bar{u}}{a^{2} \cos \varphi}\left[\frac{\partial \psi^{\prime}}{\partial \lambda} \frac{\partial \psi^{\prime}}{\partial \varphi}-\psi^{\prime} \frac{\partial^{2} \psi^{\prime}}{\partial \lambda \partial \varphi}\right]+\frac{\bar{v}}{a^{2}}\left[\left(\frac{\partial \psi^{\prime}}{\partial \varphi}\right)^{2}-\psi^{\prime} \frac{\partial^{2} \psi^{\prime}}{\partial \varphi^{2}}\right]
\end{array}\right)
$$

where $\psi^{\prime}$ denotes the perturbation stream function; $\overline{\mathrm{U}}=(\bar{u}, \bar{v})$ represents the 221 climatological mean wind velocity horizontal flow in spring; $p$ is the pressure that is normalized by $1000 \mathrm{hPa}$; and $a$ represents the Earth's radium.

We use the perturbation hypsometric equation (Li et al. 2021) as follows to 224 investigate the influence of the atmospheric circulation variation on the air temperature:

$226=\frac{g_{0}}{R}\left(\ln \frac{p_{1}}{p_{2}}\right)^{-1} \Delta Z^{\prime}$

227 where $\langle T\rangle^{\prime}$ and $\Delta Z^{\prime}$ are the anomaly or deviations from their time average between 228 two pressure surfaces $p_{1}$ and $p_{2}$, respectively, $g_{0}$ is the acceleration owing to gravity, 
and $R$ is the gas constant of dry air. According to Equation (6), the perturbation mean air temperature of the atmospheric layer is proportional to the perturbation atmospheric

231 thickness bounded by isobaric surfaces. Therefore, the atmospheric thickness anomaly 232 can be applied to represent the perturbation mean air temperature of the atmospheric 233 layer. When the atmospheric thickness is reduced, the mean air temperature of the 234 atmospheric layer drops, and vice versa. We use this perturbation hypsometric equation 235 to investigate the influence of the upper-level atmospheric circulation on the air 236 temperature anomalies.

237 We defined the NAM index used in this study as the difference in the normalized 238 zonal-mean SLP between $35^{\circ} \mathrm{N}$ and $65^{\circ} \mathrm{N}$ ( $\mathrm{Li}$ and Wang 2003). To exclude the influence 239 of global warming, all variables used in this study are detrended by removing their trends related to global warming.

\section{Synergistic effect of the preceding winter NAM and spring TNA SST}

Figure 1 shows the correlation maps between the preceding winter NAM and spring extreme temperature indices in East Asia. It can be seen from Fig. 1 that the

244 significant correlation areas for the four extreme cold indices are found across the MHEA. This indicates that when the preceding winter pNAM occurs, the spring daily minimum temperature is usually higher than normal and the number of low-temperature 247 days is less than normal in the MHEA, which further implies that the preceding winter 248 pNAM is unfavorable for the spring extreme cold events in the MHEA (Fig. 1). This 249 result is consistent with the previous study by Yin et al. (2013).

250 Based on Fig. 1, we select the domain bounded by $40^{\circ}-60^{\circ} \mathrm{N}$ and $90^{\circ}-130^{\circ} \mathrm{E}$ in 251 the MHEA as the study area. Figure 2 shows the correlation maps between the spring 252 global SSTA and spring area-averaged extreme temperature indices in the MHEA $\left(40^{\circ}-\right.$ 
$\left.60^{\circ} \mathrm{N}, 90^{\circ}-130^{\circ} \mathrm{E}\right)$. As shown in Fig. $2 \mathrm{a}$ and $2 \mathrm{~b}$, there is a large area in the TNA where

254 the SSTA is significantly positively correlated with TN10p and TX10p simultaneously.

255 This indicates that there are less spring cold days and nights in the MHEA when the 256 spring TNA SST becomes colder. Fig. $2 \mathrm{c}$ and $2 \mathrm{~d}$ shows that the spring TNA SSTA is 257 significantly negatively correlated with both TNn and TXn simultaneously, indicating 258 that when the spring TNA SST becomes colder, the spring minimum temperature in the 259 MHEA is usually higher than normal. The above results imply that the spring TNA 260 SSTA may be another crucial factor with respect to the spring extreme cold events in 261 the MHEA.

262 As the preceding winter pNAM and spring nTNA SSTA are both related to the 263 decrease and weakening of the spring extreme cold events in the MHEA, we selected 264 these two factors to investigate whether there is a synergistic effect using the method 265 proposed by Li et al. (2019a). To include more cases in our study, 0.6 standard 266 deviations was used as the threshold to select the preceding winter pNAM and spring 267 nTNA SSTA events. Table 2 lists the numbers and years of the joint events of the 268 preceding winter pNAM and spring nTNA SSTA (pNAM $\oplus$ nTNA), single preceding 269 winter pNAM events, and single spring nTNA SSTA events. Between 1961 and 2018, 270 there were 7 joint events $\mathrm{pNAM} \oplus \mathrm{nTNA}, 9$ single preceding winter pNAM events, and 2719 single spring nTNA SSTA events, and the total number accounts for more than one 272 third of all cases across the whole period.

$273 \quad$ Figure $3 \mathrm{a}$ and $3 \mathrm{~b}$ shows the time series of the spring area-averaged TN10p and $274 \mathrm{TNn}$ in the MHEA $\left(40^{\circ}-60^{\circ} \mathrm{N}, 90^{\circ}-130^{\circ} \mathrm{E}\right)$. The magnitudes of most of the spring 275 extreme cold event anomalies in the MHEA for the joint events pNAM $\oplus$ nTNA are 276 clearly far greater than those for the single preceding winter pNAM or single spring 277 nTNA SSTA events (Fig. 3a and 3b). For the joint events pNAM $\oplus$ nTNA, 6 out of 7 are 
negative (positive) TN10p (TNn) anomalies, and the other is a weak positive (negative) anomaly. However, for the single preceding winter pNAM and spring nTNA SSTA events, only one third show positive TN10p anomalies and, compared with the joint events pNAM $\oplus$ nTNA, these positive anomalies are relatively weak. This demonstrates

282 that the same-sign rate of the joint events pNAM $\oplus$ nTNA is much greater than that of 283 the single events, indicating a greater probability of negative extreme cold event anomalies in the MHEA for the cooccurrence of the preceding winter pNAM and spring nTNA SSTA than for the occurrence of only one factor. The composite area-averaged TN10p and TNn anomalies in the MHEA are -3.71 and 1.85, respectively, which are far greater than the anomaly values of the single preceding winter pNAM events $(-0.27$ and 0$)$ and single spring nTNA SSTA events $(-0.74$ and 0.19$)$. The above analysis indicates that the MHEA tends to experience a warm spring, and the extreme cold events occur far less and are weaker than normal when both the preceding winter pNAM and spring nTNA SSTA occur, which further indicates that there is a strong synergistic effect from the preceding winter pNAM and spring nTNA SSTA with respect to spring extreme cold events in the MHEA.

To further compare the spatial characteristics of the spring extreme cold anomalies from different events, Figure 4 shows the composite spatial distributions of spring $\mathrm{TN} 10 \mathrm{p}$ and $\mathrm{TNn}$ anomalies from the joint events $\mathrm{pNAM} \oplus \mathrm{nTNA}$, single preceding 297 winter pNAM events, and single spring nTNA SSTA events. Compared with the single preceding winter pNAM events and single spring nTNA SSTA events, the composite maps of extreme spring temperature indices for the joint events pNAM $\oplus$ nTNA have a 300 large same-sign area over the MHEA, extending from $70^{\circ} \mathrm{E}$ to the east side of the 301 MHEA continent, with the greatest anomaly in the central area of the MHEA (Fig. 4). 302 Based on Li et al. (2019a), the synergistic effect of the preceding winter pNAM and 
spring nTNA SSTA on the spring extreme cold events is significant in this area, especially in the region that is the most closely correlated with the NAM. The spatial distribution shown in Fig. 4 is consistent with Fig. 3, further supporting the strong synergistic effect of the preceding winter pNAM and spring nTNA SSTA on weakening

307 and decreasing the spring extreme cold events in the MHEA. As the interannual 308 variations and spatial distributions of the various extreme temperature indices anomalies across the MHEA are similar, we will focus on TN10p in the rest of this paper.

To investigate the mechanism associated with the synergistic influence of the two

312 factors on the spring extreme cold events in the MHEA, Figure 5a shows the correlation 313 map between the spring TN10p in the MHEA and the spring 500-hPa geopotential 314 height. There is an area of significantly negative correlation on the east side of the 315 Eurasian continent and over the adjacent Okhotsk Ocean. This implies that the spring 316 atmospheric circulation anomaly in this area is vital to the variation of the spring 317 extreme cold events in the MHEA. When a strong anomalous anticyclone appears in 318 this area, the extreme cold events decrease and weaken in the MHEA. Thus, we use the spring area-averaged $500-\mathrm{hPa}$ geopotential height anomaly across the domain $45^{\circ}-$ $70^{\circ} \mathrm{N}, 90^{\circ}-150^{\circ} \mathrm{E}$ as the spring MHEA anomalous anticyclone index to quantify the anomalous atmospheric circulation.

Figure $5 \mathrm{~b}$ shows the time series of the spring MHEA anomalous anticyclone index and TN10p in spring. The spring MHEA anomalous anticyclone index is highly correlated with TN10p, with a correlation coefficient of -0.75 , far exceeding the $99 \%$ confidence level. This indicates that the spring MHEA anomalous anticyclone may lead to a decrease and weakening of the spring extreme cold events in the MHEA. 
caused by horizontal temperature advection, the vertical motion of air, and diabatic heating (e.g., longwave and shortwave radiation). The atmospheric thickness mentioned in Section 2 is a key factor that can be used to investigate changes in air temperature 331 caused by changes in the atmospheric circulation (Li et al. 2021). From the perturbation 332 thermodynamic equation, horizontal temperature advection can be written as $333-\left(\boldsymbol{u}^{\prime} \frac{\partial \bar{T}}{\partial \boldsymbol{x}}+\boldsymbol{v}^{\prime} \frac{\partial \bar{T}}{\partial \boldsymbol{y}}+\overline{\boldsymbol{u}} \frac{\partial T^{\prime}}{\partial \boldsymbol{x}}+\overline{\boldsymbol{v}} \frac{\partial T^{\prime}}{\partial \boldsymbol{y}}\right)$, and the temperature change caused by the vertical 334 motion of air is represented as $-\left(\boldsymbol{\gamma}_{\boldsymbol{d}}-\boldsymbol{\gamma}\right) \boldsymbol{w}^{\prime}$. To investigate how the spring MHEA 335 anomalous anticyclone influences the spring extreme cold events in the MHEA, Fig. 5c 336 shows the correlations of the spring area-averaged horizontal temperature advection, 337 temperature change caused by the vertical motion of air, 500-1000 hPa atmospheric 338 thickness, and the difference between the net shortwave and longwave radiation flux in 339 the MHEA with the spring MHEA anomalous anticyclone index. The correlation 340 coefficient between the spring MHEA anomalous anticyclone index and area-averaged 341 horizontal temperature advection in the MHEA is 0.58 (significant at the $99 \%$ 342 confidence level), indicating that the stronger the spring MHEA anomalous anticyclone 343 is, the greater the spring horizontal warm advection in the MHEA will be. As shown in 344 Fig. 5a, the MHEA continent is located in the western part of the spring MHEA 345 anomalous anticyclone, which is featured with southerly winds. The southerly winds 346 deliver warm air from the lower latitudes to the MHEA, which favors the increase in 347 air temperature in the MHEA. In addition, the correlation coefficient between the spring 348 MHEA anomalous anticyclone and temperature increase caused by the vertical motion 349 of air in the MHEA is 0.40 , which is also significant at the $99 \%$ confidence level. This 350 reflects a scenario in which the spring MHEA anomalous anticyclone generates the 351 sinking motion over the MHEA, which in turn leads to an increase in the air temperature. 352 There is a high positive correlation coefficient (0.82) between the spring MHEA 
353 anomalous anticyclone index and the atmospheric thickness in the MHEA, and this 354 implies that the atmospheric thickness anomaly is a reflection of the upper-level 355 geopotential height anomaly. The anomalous anticyclone can weaken the spring 356 extreme cold events in the MHEA by increasing the atmospheric thickness in the 357 MHEA, because the atmospheric thickness anomaly is proportional to the change of 358 the mean air temperature of the atmospheric layer (Li et al. 2021). In addition, the 359 correlation coefficient between the spring MHEA anomalous anticyclone and the net 360 radiation flux is 0.41 , which is also above the $99 \%$ confidence level. The sinking motion 361 brought about by the spring MHEA anomalous anticyclone restricts cloud formation in 362 the MHEA. The decrease in cloud cover leads to an increase in net radiation received 363 by the surface, causing the decrease and weakening of the spring extreme cold events in the MHEA.

365 Figure 6 shows the composite maps of the spring 500-hPa geopotential height and 366 850-hPa wind anomalies for the three different types of event. In the joint events 367 pNAM $\oplus$ nTNA, there are strong positive geopotential height anomalies in the MHEA, 368 mainly around the east side of the Eurasian continent and over the adjacent Okhotsk 369 Ocean, extending from $90^{\circ} \mathrm{E}$ to around $160^{\circ} \mathrm{E}$ (Fig. 6a). However, for the single 370 preceding winter pNAM events, there is no obvious spring MHEA anomalous 371 anticyclone over East Asia, but a weak positive geopotential height anomaly in the north 372 of the MHEA (Fig. 6b). For the single spring nTNA SSTA events, a considerably weak 373 anomalous anticyclone appears over the MHEA. Compared with the joint events 374 pNAM $\oplus$ nTNA, the area of the anomalous anticyclone associated with the single spring 375 nTNA SSTA events is smaller and most of the anomalous anticyclone is around the 376 Okhotsk Ocean instead of over the east of the mid-high latitudes Eurasian continent. 377 This implies that the anomalous anticyclone can impact only a smaller area with the 
reduced strength of influence (Fig. 6c). In addition, as shown in the time series of the spring MHEA anomalous anticyclone index in Fig. 5a, the spring MHEA anomalous anticyclone index for the joint events pNAM $\oplus$ nTNA is much larger than for the two single events, and 6 out of the 7 joint events pNAM $\oplus$ nTNA have positive anomalies (the only negative anomaly is relatively weak), which is similar to the extreme temperature indices.

The above analysis indicates that the preceding winter pNAM and spring nTNA SSTA have a strong synergistic effect on the spring anomalous anticyclone over the MHEA, which means that the cooccurrence of the preceding winter pNAM and spring nTNA SSTA lead to the strong spring anomalous anticyclone over the MHEA. This strong spring anomalous anticyclone over the MHEA gives rise to a significant increase in surface air temperature over the MHEA through the processes in Fig. 5c. Thus, it is unfavorable for the spring extreme cold events in the MHEA, and the MHEA is likely to experience a warm spring. This means that taking both the preceding winter pNAM and spring nTNA SSTA into consideration while predicting and studying the spring extreme cold events in the MHEA is of vital importance.

\section{Mechanism of the synergistic effect}

Previous studies found that the East Asian surface air temperature during spring is closely correlated with the spring EASCE (Yin et al. 2013; Ye and Lau 2019; Zhou et al. 2021). The NAM in winter is closely related to the EASCE through the temperature anomalies produced by the NAM, and the EASCE anomalies that store the NAM signal can persist for a long time (Bamzai 2003; Robock et al. 2003; Saito and Cohen 2003; Saito et al. 2004). Therefore, the preceding winter pNAM can reduce the EASCE, and the EASCE plays the role of a snow cover bridge. Figure 7a shows the time series of 
the spring EASCE anomalies and spring MHEA anomalous anticyclone index. The variations of the spring MHEA anomalous anticyclone correspond well with variations

404 in the spring EASCE, with a correlation coefficient of -0.49 , which is significant at the 99\% confidence level. Figure $7 \mathrm{~b}$ shows the correlation map between the $500-\mathrm{hPa}$ 406 geopotential height and EASCE anomalies in spring. There is a significant negative 407 correlation coefficient on the MHEA continent and over the adjacent Okhotsk Ocean. 408 In addition, this large area with the negative correlation is significant at the $95 \%$ 409 confidence level, indicating the strong connection between the spring EASCE and 410 atmospheric circulation over the MHEA. Figure $7 \mathrm{~d}$ shows the composite map of the 411 spring $500-\mathrm{hPa}$ geopotential height and wind anomalies for the joint events 412 pNAM $\oplus$ nTNA. The highly correlated area in Fig. $7 \mathrm{~b}$ is similar to the area of high 413 positive geopotential height anomalies in Fig. $7 \mathrm{~d}$. This further indicates that the spring 414 anomalous anticyclone is closely related to the spring EASCE, and the spring EASCE 415 affects the spring extreme cold events in the MHEA through the atmospheric circulation 416 over the MHEA.

$417 \quad$ Figure $7 \mathrm{c}$ shows the spring EASCE anomalies for the three types of event. There 418 is a strong decrease in the spring EASCE in the joint events pNAM $\oplus$ nTNA, which can 419 lead to the strong spring anomalous anticyclone over the MHEA. However, for the two 420 types of single event, the decrease in the spring EASCE is far weaker than that for the 421 joint events pNAM $\oplus$ nTNA. In addition, the time series of spring EASCE anomalies 422 (Fig. 7a) shows that the amplitudes of the joint events pNAM $\oplus$ nTNA are greater than 423 those of the single events. It is also worth noting that 6 of the 7 pNAM $\oplus$ nTNA events 424 have positive EASCE anomalies (the only negative anomaly is also relatively weak), 425 which matches the extreme spring temperature indices and the MHEA spring 426 anomalous anticyclone index, and this means that there is a higher same-sign rate in the 
joint events pNAM $\oplus$ nTNA than that in the single spring nTNA SSTA events or single preceding winter pNAM events.

The above analysis shows that the preceding winter pNAM and spring nTNA SSTA act synergistically to reduce the spring EASCE, and the reduction in EASCE 431 leads to the strong spring anomalous anticyclone over the MHEA around the east side 432 of the Eurasian continent, which means the preceding winter pNAM and spring nTNA exert their synergistic effect on the MHEA anomalous anticyclone via the snow cover bridge. Through the process of temperature advection, the vertical motion of air, atmospheric thickness, and radiation in the MHEA, the two factors exert their synergistic effect on spring extreme cold events in the MHEA, which are greatly suppressed in the joint events pNAM $\oplus$ nTNA.

As there is an evident synergistic effect of the preceding winter pNAM and spring nTNA SSTA on the spring MHEA anomalous anticyclone, we will now consider how the spring nTNA SSTA acts synergistically with the preceding winter pNAM and further influences the air temperature in the MHEA. Figure 8a shows the composite map of the spring 500-hPa geopotential height anomalies for all spring nTNA SSTA events. The atmospheric circulation beyond the Atlantic displays a dipole mode from the polar to the extratropical area, which is an atmospheric circulation pattern similar annular mode characteristics (Fig. 8a).

This result is consistent with a previous study that demonstrate that the spring TNA SSTA can force the NAO-like atmospheric response through the wind-evaporation-sea surface temperature (WES) feedback (Wu et al. 2007). That is, when the spring TNA 451 SST drops, the atmospheric circulation favors the formation of the spring pNAM, and 
the spring pNAM will store the signal of the spring nTNA SSTA in the spring EASCE, which can release the signal into the atmosphere in the MHEA. In this process, the spring nTNA SSTA sends its signal to the atmospheric circulation in the MHEA via the atmospheric bridge of an NAO-like atmospheric response and the snow cover bridge of the EASCE. The spring nTNA-induced pNAM can be seen as the persistence of the preceding winter pNAM; i.e., the pNAM can persist from the preceding winter to spring in the joint events pNAM円nTNA.

The above analysis implies that the spring nTNA SSTA may amplify the signal of the preceding winter pNAM by inducing the spring pNAM, and the spring pNAM is a key factor in the atmospheric bridge linking the spring nTNA SSTA to the spring EASCE. To reveal how important the persistence of the pNAM is to the variability of the spring EASCE, Fig. 8b shows the spring EASCE anomalies for the different NAM combinations from the preceding winter and following spring. We divided the pNAM into three categories; i.e., only the preceding winter pNAM occurs, only the spring pNAM occurs, and cooccurrence of the preceding winter pNAM and spring pNAM. As shown in Fig. 8b, all three pNAM scenarios can induce a reduction in the spring EASCE. However, with respect to the degree of reduction, the three scenarios show different characteristics. Compared with the preceding winter-only and spring-only pNAM events, there is a much stronger negative anomaly of the spring EASCE if the preceding winter and spring pNAM both occur, and the negative spring EASCE anomaly value is -0.69 . This indicates that the persistence of the pNAM from the preceding winter to spring leads to a greater reduction in the spring EASCE. This result further demonstrates why joint events $\mathrm{pNAM} \oplus$ nTNA generate a larger spring EASCE anomaly than the two single events. 
the atmospheric bridge of the spring pNAM and the snow cover bridge of the decreased EASCE in turn, there may be another way for the spring nTNA SSTA to affect the atmospheric circulation in the MHEA. To investigate the dynamic mechanism that allows the spring nTNA SSTA to affect the atmospheric circulation in the MHEA, we 481 applied the horizontal wave activity flux proposed by Takaya and Nakamura (2001). As 482 shown in Figure 9a, the spring nTNA can excite the easterly propagating Rossby wave, and the Rossby wave energy can propagate northeastwards into the MHEA. The Rossby wave energy over the eastern side of the Eurasian continent can excite the spring MHEA anomalous anticyclone and further impact on the spring extreme cold events in the atmospheric bridge linking the spring nTNA SSTA to the spring MHEA anomalous anticyclone.

To further confirm that the eastward Rossby wave is another such atmospheric bridge, we use the approach of Rossby wave ray tracing in a horizontally nonuniform

491 background flow developed by Li and Li (2012), Li et al. (2015, 2019b, 2021), and 492 Zhao et al. $(2015,2019)$. Figure 9b shows the stationary Rossby wave trajectories in 493 the horizontally nonuniform flow for the spring nTNA SSTA events at 500-hPa. The 494 starting region is set in the TNA, there are easterly propagating Rossby wave rays along 495 the Eurasian continent, and the Rossby wave rays concentrate over the eastern side of 496 the MHEA continent. The stationary Rossby wave trajectories indicate that the 497 concentrated Rossby wave energy favors the formation of an anomalous anticyclone 498 over the MHEA, which is consistent with the wave activity flux in Fig. 9a. The Rossby 499 wave induced by the spring nTNA SSTA acts jointly with the diminished spring EASCE, 500 leading to the strong MHEA anomalous anticyclone, and then the decrease and 501 weakening of the spring extreme cold events in the MHEA. The above results show 
that the spring nTNA SSTA has a synergistic impact on the spring MHEA anomalous anticyclone jointly with the preceding winter pNAM via the snow cover bridge of the spring decreased EASCE and the atmospheric bridge of the easterly propagating Rossby wave.

\section{Summary and discussion}

In this paper, we have demonstrated that the preceding winter pNAM and the spring nTNA SSTA have a synergistic effect that leads to a significant decrease in extreme cold events in the MHEA. Both the single preceding winter pNAM and single spring nTNA SSTA can slightly decrease and weaken the extreme cold events in the MHEA. However, when both factors occur, the reduction in intensity of the extreme cold events is much greater than that caused by either factor alone, and the probability of a weakened extreme cold event is far greater than that associated with a single factor event. It is worth noting that the region affected is not confined to northeast China, but covers a much larger area of the MHEA.

Figure 10 summarizes the process associated with the synergistic effect of the preceding winter pNAM and the spring nTNA SSTA on the extreme cold events in the MHEA. The preceding winter pNAM can store its signal in the EASCE, which diminishes the simultaneous EASCE. Owing to the persistence of the snow cover, the negative EASCE anomaly can persist into the spring of the following year (Bamzai 2003; Robock et al. 2003; Saito and Cohen 2003; Saito et al. 2004). This process is seen as the snow cover bridge sending the signal from the preceding winter pNAM to the atmospheric circulation over the MHEA. In spring, the occurrence of the spring nTNA SSTA forces a positive NAO-like atmospheric response, leading to the formation of the anomalous high (low) pressure over the subtropical Atlantic (subpolar area of the 
Atlantic; Wu et al. 2007). As the NAO can be seen as a branch of the NAM over the

527 Atlantic region, the spring TNA SST cooling could result in the spring pNAM. Then, 528 the spring pNAM induced by the spring nTNA SSTA can further reduce the 529 simultaneous EASCE.

530 By comparing the response of the spring EASCE anomalies with different NAM 531 phase combinations in the preceding winter and spring, we find that the spring EASCE 532 exhibits the greatest negative anomaly when the pNAM persists from the preceding 533 winter to the following spring. As a result, by inducing the pNAM atmospheric response 534 in spring, the spring nTNA SSTA and the preceding winter pNAM exert a synergistic 535 effect that causes the great reduction in the spring EASCE. The EASCE is closely 536 correlated with the atmospheric pressure over the eastern side of the MHEA continent. 537 Thus, when the spring EASCE diminishes, an anomalous anticyclone forms over the 538 MHEA, which is strongly related to the spring extreme cold events. The above 539 processes show that the positive spring NAO-like atmospheric response induced by the 540 spring nTNA SSTA is the atmospheric bridge, and the decrease in spring EASCE is the 541 snow cover bridge. These two bridges together send the signal of the spring nTNA 542 SSTA to the atmospheric circulation over the MHEA.

543 As a result of the significant decrease in the spring EASCE (i.e., the snow cover 544 bridge), the two factors also have an evident synergistic effect on the spring MHEA 545 anomalous anticyclone, which is strongest in the joint events pNAM $\oplus$ nTNA. We found 546 that the strength of the spring MHEA anomalous anticyclone is closely related to 547 horizontal temperature advection, the temperature increase caused by the vertical 548 motion of air, atmospheric thickness, and net shortwave and longwave radiation in the 549 MHEA. The anomalous southerly winds on the western side of the spring MHEA 550 anomalous anticyclone cause warm advection that brings warm air from the south and 
551 leads to the increase in air temperature and the weakening of the extreme cold events 552 in spring in the MHEA.

553 In addition, according to the perturbation hypsometric equation, the increased 554 atmospheric thickness can lead to an increase in the mean air temperature of the 555 atmospheric layer. Furthermore, the anomalous high pressure over the MHEA can 556 become a barrier that is able to hinder the southern movement of the cold air from the 557 polar area. Therefore, the above process further decreases and weakens the spring 558 extreme cold events in the MHEA.

559 In addition to the above atmospheric processes, the anomalous high pressure can 560 also change the net radiation in the MHEA. The sinking motion caused by the 561 anomalous high pressure hinders cloud formation, and thereby increases net radiation 562 received at the surface, and further leads to warmer air temperatures, and less and 563 weaker spring extreme cold events than normal in the MHEA.

564 In addition to influencing the atmospheric circulation over the MHEA through the 565 snow cover bridge of the spring EASCE, the spring nTNA SSTA has an additional 566 impact on the atmospheric circulation over the MHEA via the atmospheric bridge of 567 the Rossby wave train. We have revealed that the Rossby wave energy over the Eurasian 568 continent favors the propagation of the Rossby wave downstream when the spring 569 nTNA SSTA occurs, which can affect the 500-hPa geopotential height over the MHEA 570 and favor the formation of the spring MHEA anomalous anticyclone. This atmospheric 571 process further increases the air temperature and weakens the spring extreme cold 572 events. In the end, the MHEA may experience a warmer spring.

573 In this paper, we have analyzed the synergistic effect of the preceding winter 574 pNAM and spring nTNA SSTA on the interannual variability of the spring extreme cold 575 events in the MHEA. However, one extreme cold case in East Asia may be influenced 
by some weather processes, such as the cold vortex. Thus, the whole process of one extreme temperature case needs the further detailed analysis. Note that we analyzed only two influencing factors over the interannual timescale in this study because of the length of the available dataset, but extreme temperature can be influenced by more than these two factors. If we take multiple factors into consideration, observational data covering a much longer period will be required to obtain an adequate sample size. Consequently, a longer observational dataset and comprehensive consideration of the synergistic effects of multiple factors will be required in a future study.

\section{Acknowledgement}

Hao Wang and Yina Diao contributed equally to this work. We wish to thank all the data providers. This work is supported by the National Natural Science Foundation of China (NSFC) Project (41790474), Shandong Natural Science Foundation Project (ZR2019ZD12), and Fundamental Research Funds for the Central Universities (201962009). We are grateful to Center for High Performance Computing and System Simulation, Pilot National Laboratory for Marine Science and Technology (Qingdao) for providing computing resource.

\section{References}

Bamzai A (2003) Relationship between snow cover variability and Arctic Oscillation index on a hierarchy of time scales. Int J Climatol 23(2):131-142

Chen TC, Yen MC, Huang WR, Gallus WA (2002) An East Asian cold surge: case study. Mon Weather Rev 130(9):2271-2290

Chen TC, Huang WR, Yoon J (2004) Interannual variation of the East Asian cold surge activity. J Clim 17(2):401-413 
Chen S, Wu R, Liu Y (2016) Dominant modes of interannual variability in Eurasian surface air temperature during boreal spring. J Clim 29:1109-1125

Cheung HN, Zhou W, Mok HY, Wu MC (2012) Relationship between Ural-Siberian blocking and the East Asian winter monsoon in relation to the Arctic Oscillation and the El Nino-Southern Oscillation. J Clim 25(12):4242-4257

Dunn RJH, Alexander LV, Donat MG et al (2020) Development of an updated global land in situ-based data set of temperature and precipitation extremes: HadEX3. J Geophys Res Atmos 125(16):e2019JD032263

Easterling DR (2000) Climate extremes: observations, modeling, and impacts. Science 289(5487):2068-2074

Hoskins BJ, Karoly DJ (1981) The steady linear response of a spherical atmosphere to thermal and orographic forcing. J Atmos Sci 38:1179-1196

Huang J, Yu H, Guan X, Wang G, Guo R (2016) Accelerated dryland expansion under climate change. Nat Clim Change 6:166-171

Gong DY, Ho CH (2002) The Siberian high and climate change over middle to high latitudeAsia. Theor Appl Climatol 72(1):1-9

Gong DY, Yang J, Kim SJ, Gao Y, Guo D, Zhou T, Hu M (2011) Spring Arctic Oscillation-East Asian summer monsoon connection through circulation changes over the western North Pacific. Clim Dyn 37:2199-2216

Jeong J-H, Kim B-M, Ho C-H, Noh Y-H (2008) Systematic variation in wintertime precipitation in East Asia by MJO-induced extratropical vertical motion. J Clim 21(4):788-801

Kalnay E, Kanamitsu M, Kistler R et al (1996) The NCEP/NCAR 40-year reanalysis project. Bull Am Meteorol Soc 77(3):437-471

Karoly DJ (1983) Rossby wave propagation in a barotropic atmosphere. Dyn Atmos Oceans 7:111-125

Katz RW, Brown BG (1992) Extreme events in a changing climate: variability is more important than averages. Clim Chang 21(3):289-302

Li SL (2004) Impact of northwest Atlantic SST anomalies on the circulation over the Ural Mountains during early winter. J Meteor Soc Japan 82: 971-988

Li Y, Li JP (2012) Propagation of planetary waves in the horizontal non-uniform basic flow (in Chinese). Chin J Geophys 55(2):361-371

Li L, Nathan TR (1997) Effects of low-frequency tropical forcing on intraseasonal tropical-extratropical interactions. J Atmos Sci 54:332-346

Li JP, Ruan CQ (2018) The North Atlantic-Eurasian teleconnection in summer and its effects on Eurasian climates. Environ Res Lett 13:024007

Li JP, Wang JXL (2003) A modified zonal index and its physical sense. Geophys Res Lett 30:1632

Li JP, Wu ZW (2012) Importance of autumn Arctic sea ice to northern winter snowfall. Proc Natl Acad Sci 109:E1898

Li F, Wang HJ, Liu JP (2014) The strengthening relationship between Arctic Oscillation and ENSO after the mid-1990s. Int J Climatol 34:2515-2521

Li Y, Li JP, Jin FF, Zhao S (2015) Interhemispheric propagation of stationary Rossby waves in the horizontally nonuniform background flow. J Atmos Sci 72(8):3233- 
Li JP, Zheng F, Sun C, Feng J, Wang J (2019a) Pathways of influence of the Northern Hemisphere mid-high latitudes on East Asian climate: a review. Adv Atmos Sci 36:902-921

Li Y, Feng J, Li JP, Hu X (2019b) Equatorial windows and barriers for stationary Rossby wave propagation. J Clim 32:6117-6135

Li JP, Xie TJ, Tang XX, Wang H, Sun C, Feng J, Zheng F, Ding RQ (2021) Influence of the NAO on wintertime surface air temperature over the East Asia: Multidecadal variability and decadal prediction. Adv Atmos Sci.

Lin J, Wu B, Zhou T (2016) Is the interdecadal circumglobal teleconnection pattern excited by the Atlantic multidecadal Oscillation? Atmos Ocean Sci Lett 9:451-457

Liu YY, Wang L, Zhou W, Chen W (2014) Three Eurasian teleconnection patterns: spatial structures, temporal variability, and associated winter climate anomalies. Clim Dyn 42:2817-2839

Meehl GA, Tebaldi C, Adams-Smith D (2016) US daily temperature records past, present, and future. Proc Natl Acad Sci 113(49):13977-13982

Monerie P-A, Robson J, Dong B et al (2019) Effect of the Atlantic multidecadal variability on the global monsoon. Geophys Res Lett 46:1765-1775

Morice CP, Kennedy JJ, Rayner NA, Jones PD (2012) Quantifying uncertainties in global and regional temperature change using an ensemble of observational estimates: The HadCRUT4 dataset. J Geophys Res 117:D08101

Nangombe S, Zhou T, Zhang W, Wu B, Hu S, Zou L, Li D (2018) Record-breaking climate extremes in Africa under stabilized $1.5^{\circ} \mathrm{C}$ and $2{ }^{\circ} \mathrm{C}$ global warming scenarios. Nat Climate Change 8(5):375

Qiao S, Feng G (2016) Impact of the December North Atlantic Oscillation on the following February East Asian trough. J Geophys Res 121:10074-10088

Park TW, Jeong JH, Ho CH, Kim SJ (2008) Characteristics of atmospheric circulation associated with cold surge occurrences in East Asia: a case study during 2005/06 winter. Adv Atmos Sci 25(5):791-804

Park TW, Ho CH, Deng Y (2014) A synoptic and dynamical characterization of wavetrain and blocking cold surge over East Asia. Clim Dyn 43(3):753-770

Rayner NA, Parker DE, Horton EB, Folland CK, Alexander LV, Rowell DP, Kent EC, Kaplan A (2003) Global analyses of sea surface temperature, sea ice, and night marine air temperature since the late nineteenth century. J Geophys Res 108:4407

Robinson DA, Estilow TW, Program NOAACDR (2012) NOAA Climate Data Record (CDR) of Northern Hemisphere (NH) Snow Cover Extent (SCE), version 1. NOAA Natl Cent Environ Inf.

Robock A, Mu M, Vinnikov K, Robinson D (2003) Land surface conditions over Eurasia and Indian summer monsoon rainfall. J Geophys Res Atmos 108:4131

Saito K, Cohen J (2003) The potential role of snow cover in forcing interannual variability of the major Northern Hemisphere mode. Geo Res Lett 30(6):1302

Saito K, Yasunari T, Cohen J (2004) Changes in the sub-decadal covariability between Northern Hemisphere snow cover and the general circulation of the atmosphere. Int J Climatol 24(1):33-44 
Screen JA, Simmonds I (2013) Exploring links between Arctic amplification and midlatitude weather. Geophys Res Lett 40:959-964

Sun Y, Li JP (2021) Synergistic effect of El Niño and the North Pacific Oscillation on wintertime precipitation over southeastern China and the East China Sea Kuroshio area. Clim Dyn in press

Sun Y, Zhang X, Zwiers FW, Song L, Wan H, Hu T, Yin H, Ren G (2014) Rapid increase in the risk of extreme summer heat in eastern China. Nat Clim Chang 4(12):10821085

Sun C, Li J, Zhao S (2015) Remote influence of Atlantic multidecadal variability on Siberian warm season precipitation. Sci Rep 5:16853

Takaya K, Nakamura H (2001) A formulation of a phase-independent wave activity flux for stationary and migratory quasi geostrophic eddies on a zonally varying basic flow. J Atmos Sci 58:608-627

Thompson DW, Wallace JM (1998) The Arctic Oscillation signature in the wintertime geopotential height and temperature fields. Geophys Res Lett 25:1297-1300

Thompson DW, Wallace JM (2000) Annular modes in the extratropical circulation. Part I: month-to-month variability. J Clim 13:1000-1016

Wallace JM, Gutzler DS (1981) Teleconnections in the geopotential height field during the Northern Hemisphere winter. Mon Wea Rev 109:784-812

Whitham G (1960) A note on group velocity. J Fluid Mech 9:347-352

Wu L, He F, Liu Z, Li C (2007) Atmospheric teleconnections of tropical Atlantic variability: interhemispheric, tropical-extratropical, and cross-basin interactions. J Clim 20:856-870

Wu R, Yang S, Liu S et al (2011) Northeast China summer temperature and North Atlantic SST. J Geophys Res 116:D16116

Wu ZW, Lin H, Li JP, Jiang ZH, Ma TT (2012) Heat wave frequency variability over North America: two distinct leading modes. J Geophys Res Atmos 117:D02102

Wu B, Lin J, Zhou T (2016) Interdecadal circumglobal teleconnection pattern during boreal summer. Atmos Sci Lett 17:446-452

Xin X, Zhang L, Zhang J, Wu T, Fang Y (2013) Climate change projections over East Asia with BCC_CSM1.1 climate model under RCP scenarios. J Meteorol Soc Jpn 91(4):413-429

Ye KH, Lau NC (2019) Characteristics of Eurasian snowmelt and its impacts on the land surface and surface climate. Clim Dyn 52:1115-1138

Yin S, Feng J, Li JP (2013) Influences of the preceding winter Northern Hemisphere annular mode on the spring extreme low temperature events in the north of eastern China (in Chinese with English abstract). Acta Meteorol Sin 71(1):96-108

Zhang C, Wu R, Wang Z (2019) Impacts of summer North Atlantic sea surface temperature anomalies on the East Asian winter monsoon variability. J Clim 32(19):6513-6532

Zhao S, Li JP, Li Y (2015) Dynamics of an interhemispheric teleconnection across the critical latitude through a southerly duct during boreal winter. J Clim 28(19):74377456

Zhao S, Li JP, Li Y, Jin F-F, Zheng J (2019) Interhemispheric influence of Indo-Pacific 
733

734

735

736

737

738 convection oscillation on Southern Hemisphere rainfall through southward propagation of Rossby waves. Clim Dyn 52(5-6):3203-3221

Zhou J, Zuo Z, He Q (2021) Influence of Eurasian spring snowmelt on surface air temperature in late spring and early summer. J Clim 34(20):8191-8204 
Table 1. Datasets employed in this study.

\begin{tabular}{|c|c|c|c|}
\hline Variable & Period of record & Spatial resolution & Source \\
\hline SST & 1870-present & $1^{\circ} \times 1^{\circ}$ & $\begin{array}{l}\text { HadISST1 (version 1.1) from } \\
\text { the Met Office Hadley Center } \\
\text { (Rayner et al. 2003) }\end{array}$ \\
\hline $\begin{array}{c}\text { Extreme temperature } \\
\text { indices }\end{array}$ & $1901-2018$ & $1.25^{\circ} \times 1.875^{\circ}$ & $\begin{array}{l}\text { HadEX3 from the Met Office } \\
\text { Hadley Center (Dunn et al. } \\
\text { 2020) }\end{array}$ \\
\hline $\begin{array}{l}\text { Geopotential height, } \\
\text { winds, vertical } \\
\text { velocity (omega), air } \\
\text { temperature and sea } \\
\text { level pressure }\end{array}$ & 1949-present & $2.5^{\circ} \times 2.5^{\circ}$ & $\begin{array}{c}\text { National Centers for } \\
\text { Environmental Prediction- } \\
\text { National Center for } \\
\text { Atmospheric Research } \\
\text { (NCEP-NCAR) reanalysis } \\
\text { version } 1 \text { (Kalnay et al. 1996) }\end{array}$ \\
\hline $\begin{array}{c}\text { The Global SAT } \\
\text { time series }\end{array}$ & 1850-present & / & $\begin{array}{l}\text { HadCRUT4 from Met Office } \\
\text { Hadley Center (Morice et al. } \\
\text { 2012) }\end{array}$ \\
\hline $\begin{array}{l}\text { Eurasia snow cover } \\
\text { extent (EASCE) } \\
\text { time series }\end{array}$ & 1966-present & / & $\begin{array}{c}\text { The Northern Hemisphere } \\
\text { snow cover extent climate } \\
\text { data record (NH SCE CDR } \\
\text { v01r01) from the Global } \\
\text { Snow Lab of Rutgers } \\
\text { University (Robinson et al. } \\
\text { 2012) }\end{array}$ \\
\hline
\end{tabular}

741 
743 Table 2. Numbers and years of the joint events of preceding winter pNAM and spring nTNA SSTA (pNAM $\oplus$ nTNA), single preceding winter pNAM events and single spring nTNA SSTA events.

\begin{tabular}{cccc}
\hline & $\begin{array}{c}\text { Joint events of preceding } \\
\text { winter pNAM and spring } \\
\text { nTNA (pNAM } \oplus \text { nTNA) }\end{array}$ & $\begin{array}{c}\text { single preceding winter } \\
\text { pNAM events }\end{array}$ & $\begin{array}{c}\text { single spring nTNA SSTA } \\
\text { events }\end{array}$ \\
\hline Numbers & 7 & 9 & 9 \\
Years & $\begin{array}{c}1975,1976,1989,1990, \\
2000,2002,2008\end{array}$ & $\begin{array}{c}1973,1983,1988,1992,1993, \\
1995,1999,2007,2016\end{array}$ & $\begin{array}{c}1974,1985,1986,1991,1994, \\
2001,2009,2014,2015\end{array}$ \\
\hline
\end{tabular}

746

747

748 
Fig. 1. Correlation maps between the preceding winter NAM and spring extreme temperature indices in East Asia. (a) TN10p. (b) TX10p. (c) TNn. (d) TXn. Dotted areas indicate significant values at the $95 \%$ confidence level based on the Student $t$-test.

Fig. 2. Correlation maps between the spring global SSTA and spring area-averaged extreme temperature indices in the MHEA $\left(40^{\circ}-60^{\circ} \mathrm{N}, 90^{\circ}-130^{\circ} \mathrm{E}\right)$. (a) TN10p. (b) TX10p. (c) TNn. (d) TXn. Dotted areas indicate significant values at the $95 \%$ confidence level based on the Student $t$-test.

Fig. 3. Time series of the spring area-averaged (a) TN10p (\%) and (b) TNn $\left({ }^{\circ} \mathrm{C}\right)$ in the MHEA $\left(40^{\circ}-60^{\circ} \mathrm{N}, 90^{\circ}-130^{\circ} \mathrm{E}\right)$. The red, green and blue dots represent the joint events of preceding winter pNAM and spring nTNA SSTA (pNAM $\oplus$ nTNA), single preceding winter pNAM events and single spring nTNA SSTA events respectively.

Fig. 4. Composite maps of spring extreme temperature indices for different events. (a) TN10p (\%) for the joint events of preceding winter pNAM and spring nTNA SSTA (pNAM $\oplus$ nTNA). The white dotted areas indicate the synergistic effect of preceding winter pNAM and spring nTNA SSTA. The white contour lines indicate significant values at the $95 \%$ confidence level based on the Student $t$-test. (b) As in (a) but for spring TNn $\left({ }^{\circ} \mathrm{C}\right)$. (c) As in (a), but for the single preceding winter pNAM events. (d) As in (b), but for the single preceding winter pNAM events. (e) As in (a), but for the single spring nTNA SSTA events. (f) As in (b), but for the single spring nTNA SSTA events.

Fig. 5. (a) The correlation map between the spring TN10p in the MHEA and spring $500-\mathrm{hPa}$ geopotential height. Dotted areas indicate significant values at the $95 \%$ confidence level based on the Student $t$-test. (b) Time series of the spring MHEA anomalous anticyclone index and TN10p in spring. (c) Correlations of the spring areaaveraged horizontal temperature advection (TA), temperature change caused by the vertical motion (VM), 500-1000 hPa atmosphere thickness (AT), difference between the net shortwave and longwave radiation flux (SR-LR) in the MHEA with the spring MHEA anomalous anticyclone index.

Fig. 6. Composite maps of the spring 500-hPa geopotential height (gpm; shaded) and 850-hPa winds ( $\mathrm{m} \mathrm{s}^{-1}$; vectors) at for (a) the joint events of preceding winter pNAM and spring nTNA (pNAM $\oplus$ nTNA), (b) single preceding winter pNAM events and (c) single spring nTNA SSTA events. The white dotted areas in (a) indicate the synergistic effect of preceding winter pNAM and spring nTNA SSTA. The white contour lines indicate significant values at the $95 \%$ confidence level based on the Student $t$-test.

Fig. 7. (a) Time series of the spring EASCE anomalies (blue line, unit: $10^{6} \mathrm{~km}^{2}$ ) and spring MHEA anomalous anticyclone index (green line). (b) Correlation between the 
geopotential height (gpm) at 500-hPa and EASCE anomalies $\left(10^{6} \mathrm{~km}^{2}\right)$ in spring. 792 Dotted areas indicate the significant values at the $95 \%$ confidence level based on the 793 Student $t$-test. (c) The spring area-averaged EASCE anomalies $\left(10^{6} \mathrm{~km}^{2}\right)$ for the joint 794 events pNAM $\oplus$ nTNA (red), single preceding winter pNAM events (green) and single spring nTNA SSTA events (blue) in spring. (d) The composite map of spring $500-\mathrm{hPa}$ geopotential height (gpm; shaded) and $850-\mathrm{hPa}$ winds $\left(\mathrm{m} \mathrm{s}^{-1}\right.$; vectors) for the joint events pNAM $\oplus$ nTNA.

Fig. 8. (a) The composite map of spring 500-hPa geopotential height (gmp) for all the spring nTNA SSTA events. (b) The spring EASCE anomalies $\left(10^{6} \mathrm{~km}^{2}\right)$ for different 801 NAM combinations. The red, green and blue bars represent the spring-only pNAM events, preceding winter-only pNAM events and cooccurrence of the spring and preceding winter pNAM respectively.

Fig. 9. (a) The composite map of spring 500-hPa T-N wave activity flux ( $\mathrm{m}^{2} \mathrm{~s}^{-2}$; vectors) and anomalous QG stream function $\left(\mathrm{m}^{2} \mathrm{~s}^{-1}\right.$; shaded) for all the spring nTNA SSTA events. (b) Spring stationary Rossby wave trajectories in the horizontally nonuniform flow (blue curves) with zonal wavenumber $k=4$ for all the spring nTNA SSTA events. The black dots denote the Rossby wave source. The shaded area is the climatological mean $500-\mathrm{hPa}$ zonal wind $\left(\mathrm{m} \mathrm{s}^{-1}\right)$. The Rossby wave ray tracing is calculated by adopting the approach by $\mathrm{Li}$ and $\mathrm{Li}(2012)$, Li et al. $(2015 ; 2019 b ; 2021)$ and Zhao et 812 al. (2015).

Fig. 10. The schematic diagram showing the synergistic effect of the preceding winter pNAM and spring nTNA SSTA on the spring extreme cold events in the MHEA. 


\section{$818 \quad$ Figure 1}
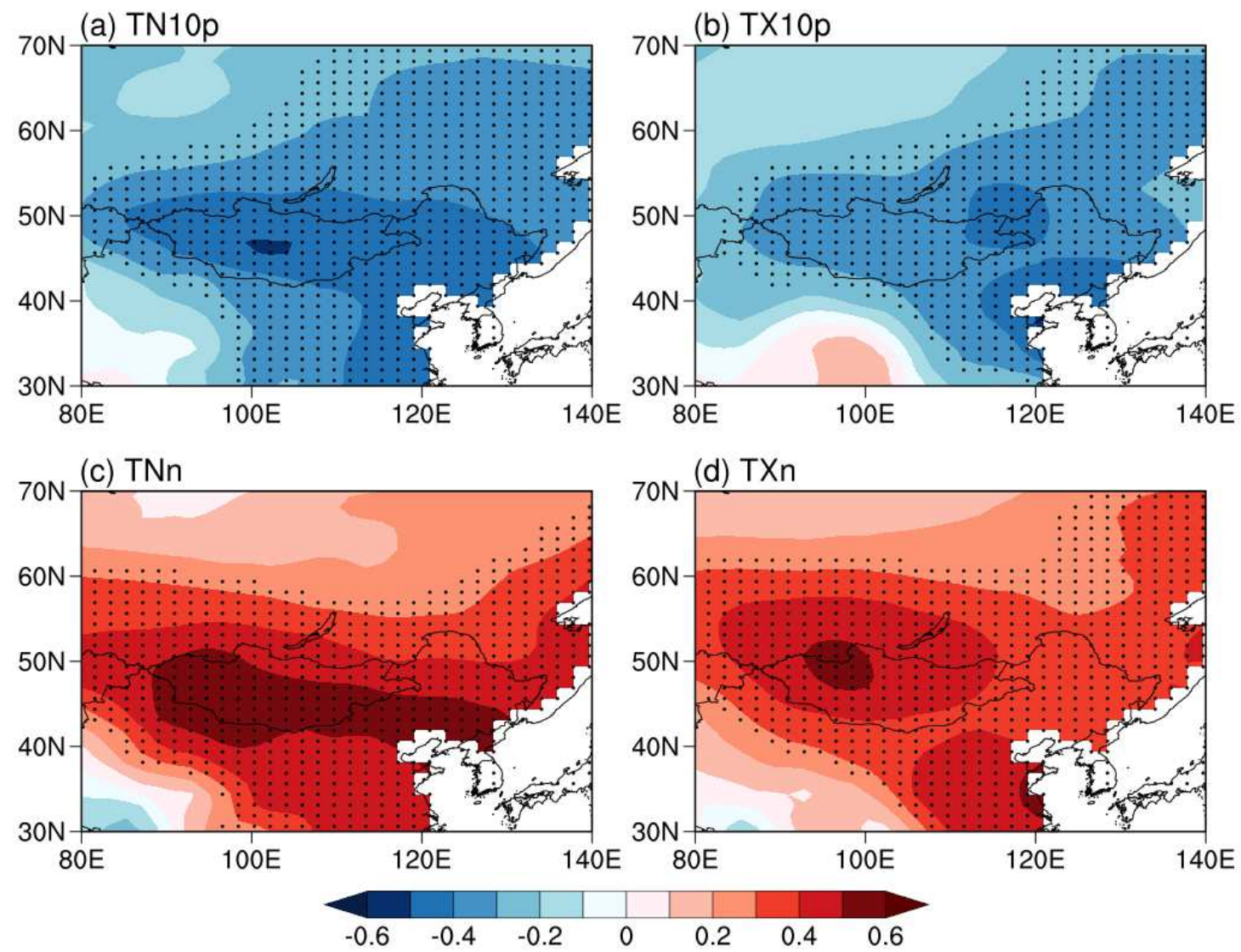

820 Fig. 1. Correlation maps between the preceding winter NAM and spring extreme 821 temperature indices in East Asia. (a) TN10p. (b) TX10p. (c) TNn. (d) TXn. Dotted areas 822 indicate significant values at the $95 \%$ confidence level based on the Student $t$-test. 
Figure 2
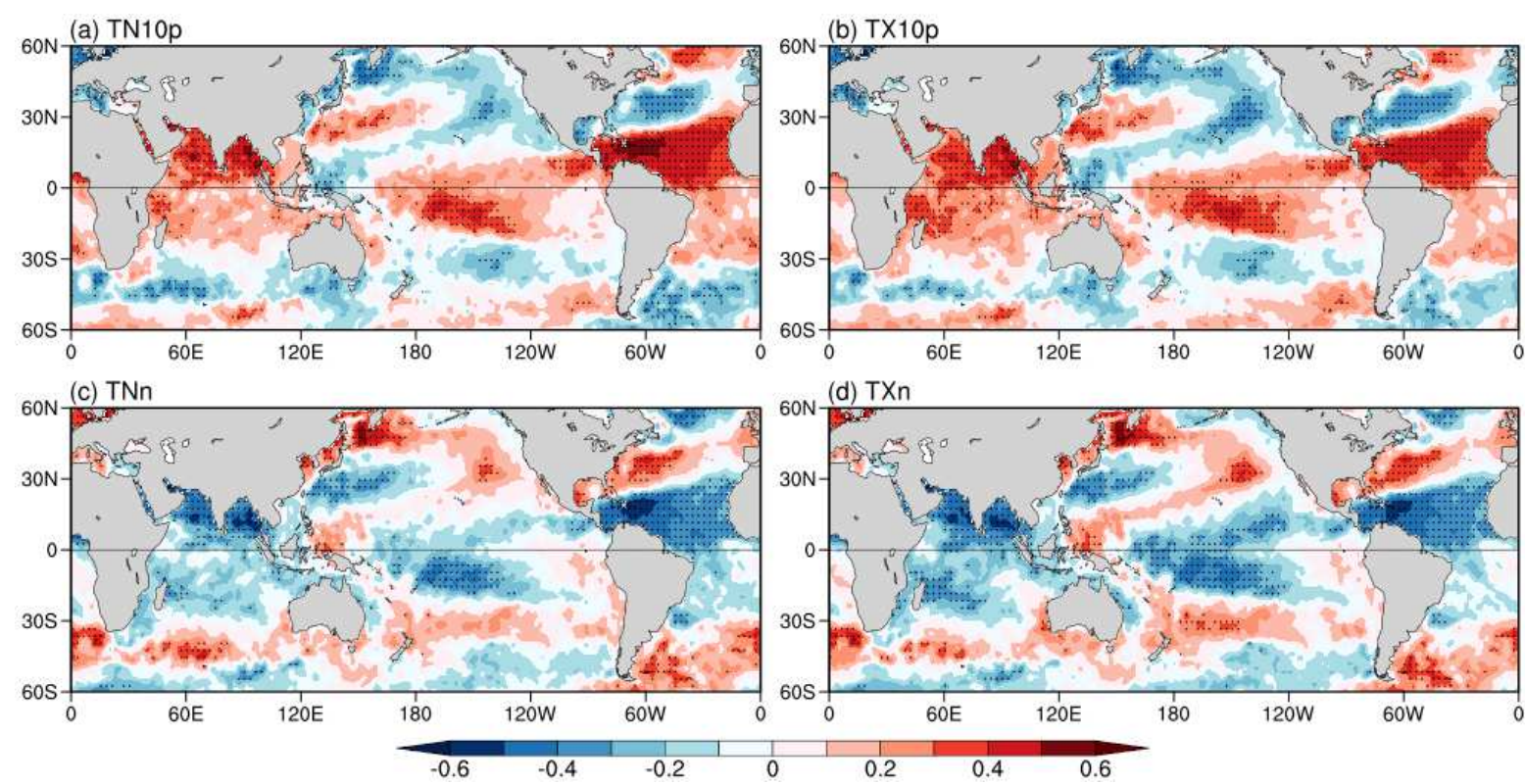

Fig. 2. Correlation maps between the spring global SSTA and spring area-averaged extreme temperature indices in the MHEA $\left(40^{\circ}-60^{\circ} \mathrm{N}, 90^{\circ}-130^{\circ} \mathrm{E}\right)$. (a) TN10p. (b) TX10p. (c) TNn. (d) TXn. Dotted areas indicate significant values at the 95\% confidence level based on the Student $t$-test. 

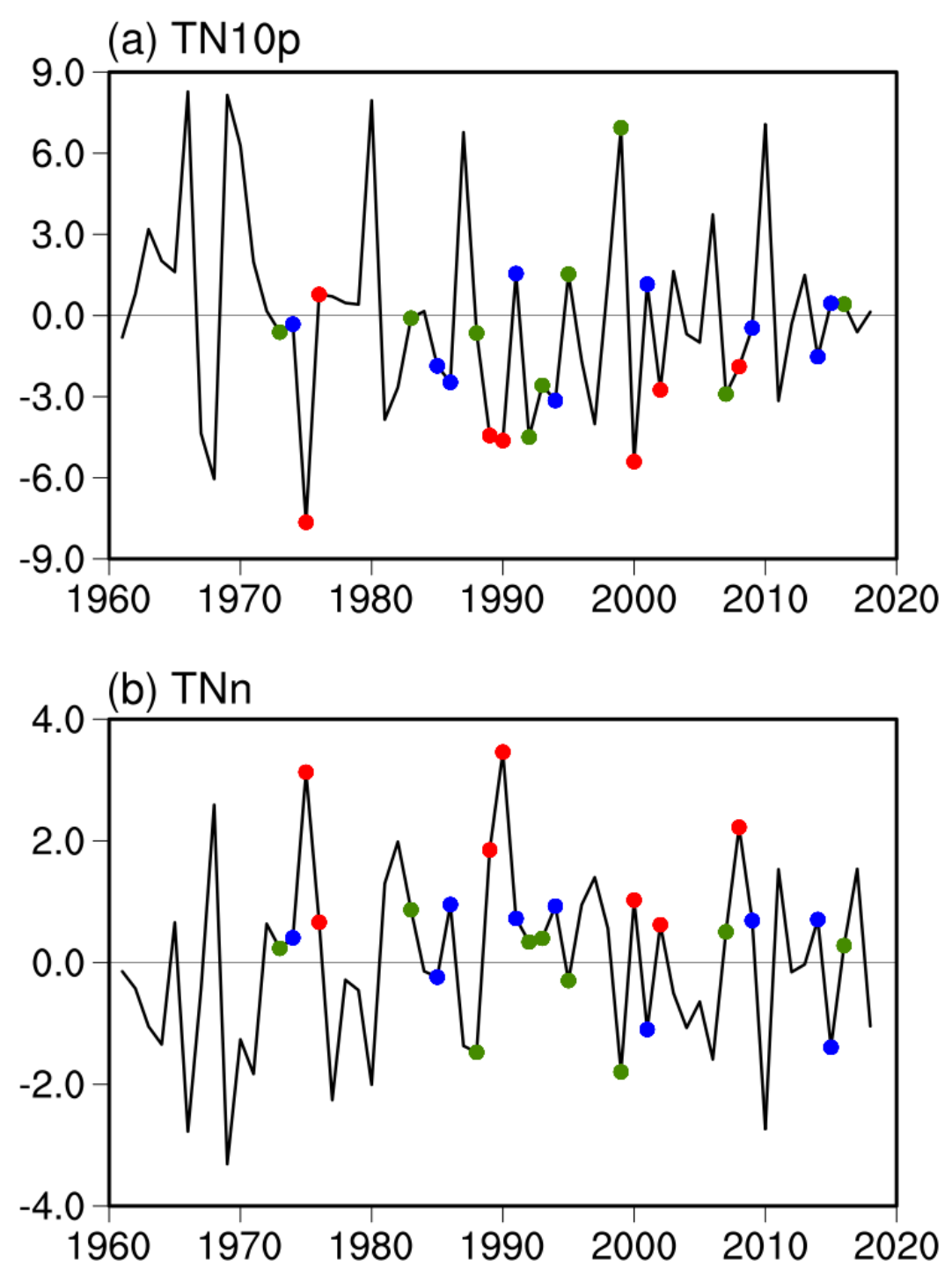

Fig. 3. Time series of the spring area-averaged (a) TN10p (\%) and (b) TNn $\left({ }^{\circ} \mathrm{C}\right)$ in the MHEA $\left(40^{\circ}-60^{\circ} \mathrm{N}, 90^{\circ}-130^{\circ} \mathrm{E}\right)$. The red, green and blue dots represent the joint events of preceding winter pNAM and spring nTNA SSTA (pNAM $\oplus$ nTNA), single preceding winter pNAM events and single spring nTNA SSTA events respectively. 

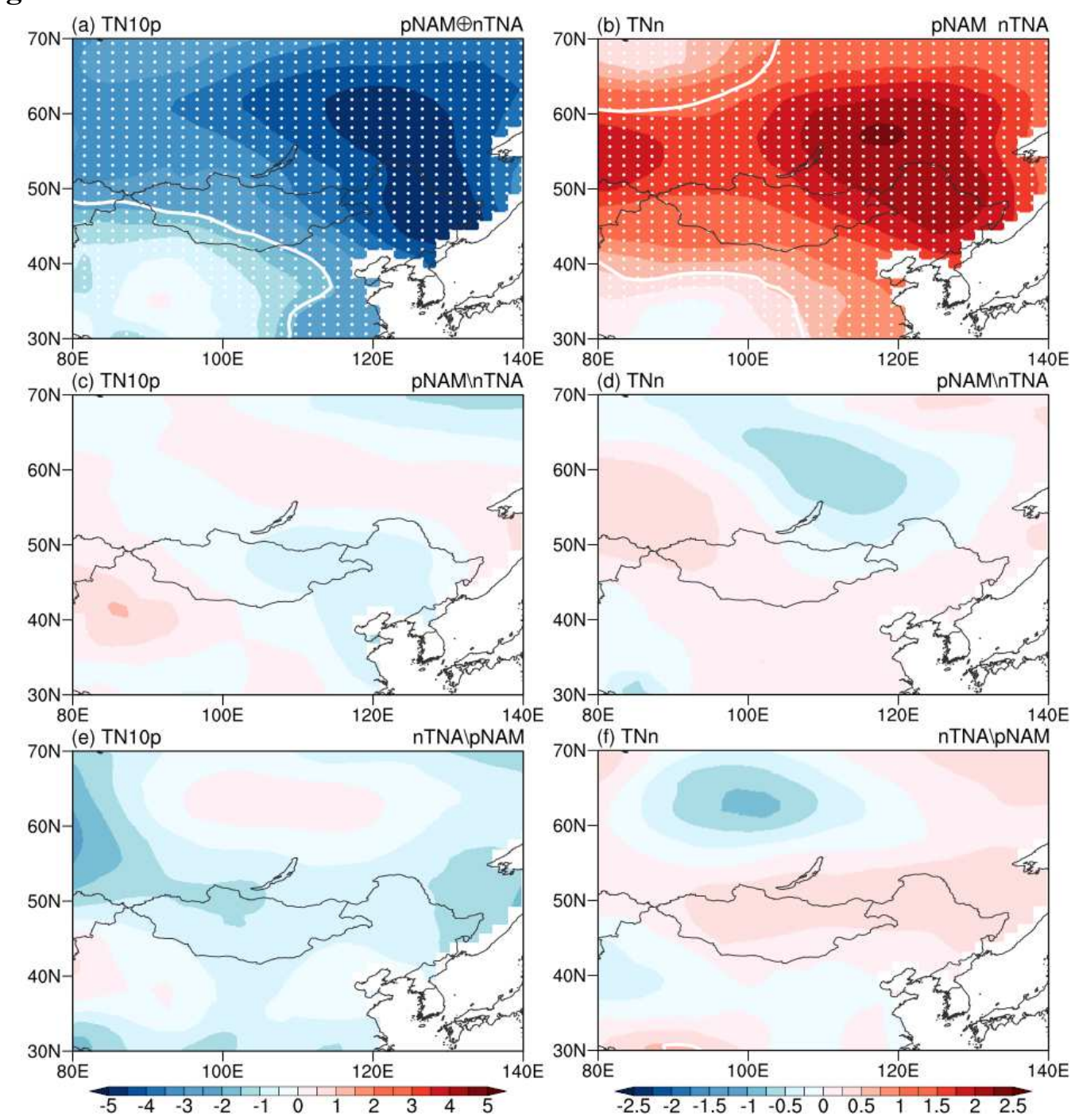

Fig. 4. Composite maps of spring extreme temperature indices for different events. (a) TN10p (\%) for the joint events of preceding winter pNAM and spring nTNA SSTA (pNAM $\oplus \mathrm{nTNA}$ ). The white dotted areas indicate the synergistic effect of preceding winter pNAM and spring nTNA SSTA. The white contour lines indicate significant values at the 95\% confidence level based on the Student $t$-test. (b) As in (a) but for spring TNn $\left({ }^{\circ} \mathrm{C}\right)$. (c) As in (a), but for the single preceding winter pNAM events. (d) As in (b), but for the single preceding winter pNAM events. (e) As in (a), but for the single spring nTNA SSTA events. (f) As in (b), but for the single spring nTNA SSTA events. 

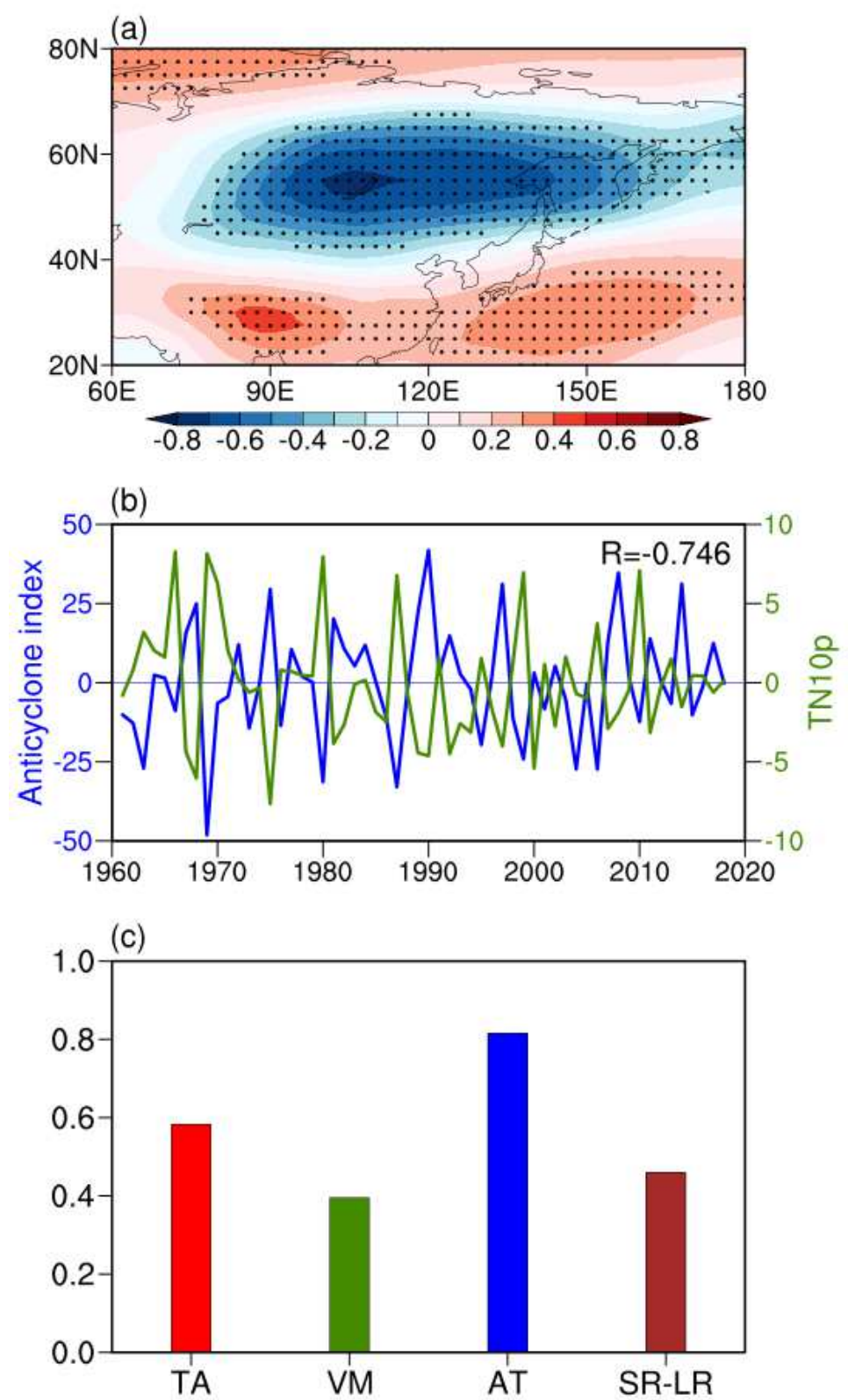

Fig. 5. (a) The correlation map between the spring TN10p in the MHEA and spring $500-\mathrm{hPa}$ geopotential height. Dotted areas indicate significant values at the $95 \%$

854 confidence level based on the Student $t$-test. (b) Time series of the spring MHEA anomalous anticyclone index and TN10p in spring. (c) Correlations of the spring areaaveraged horizontal temperature advection (TA), temperature change caused by the vertical motion of air (VM), 500-1000 hPa atmosphere thickness (AT), difference between the net shortwave and longwave radiation flux (SR-LR) in the MHEA with the spring MHEA anomalous anticyclone index. 

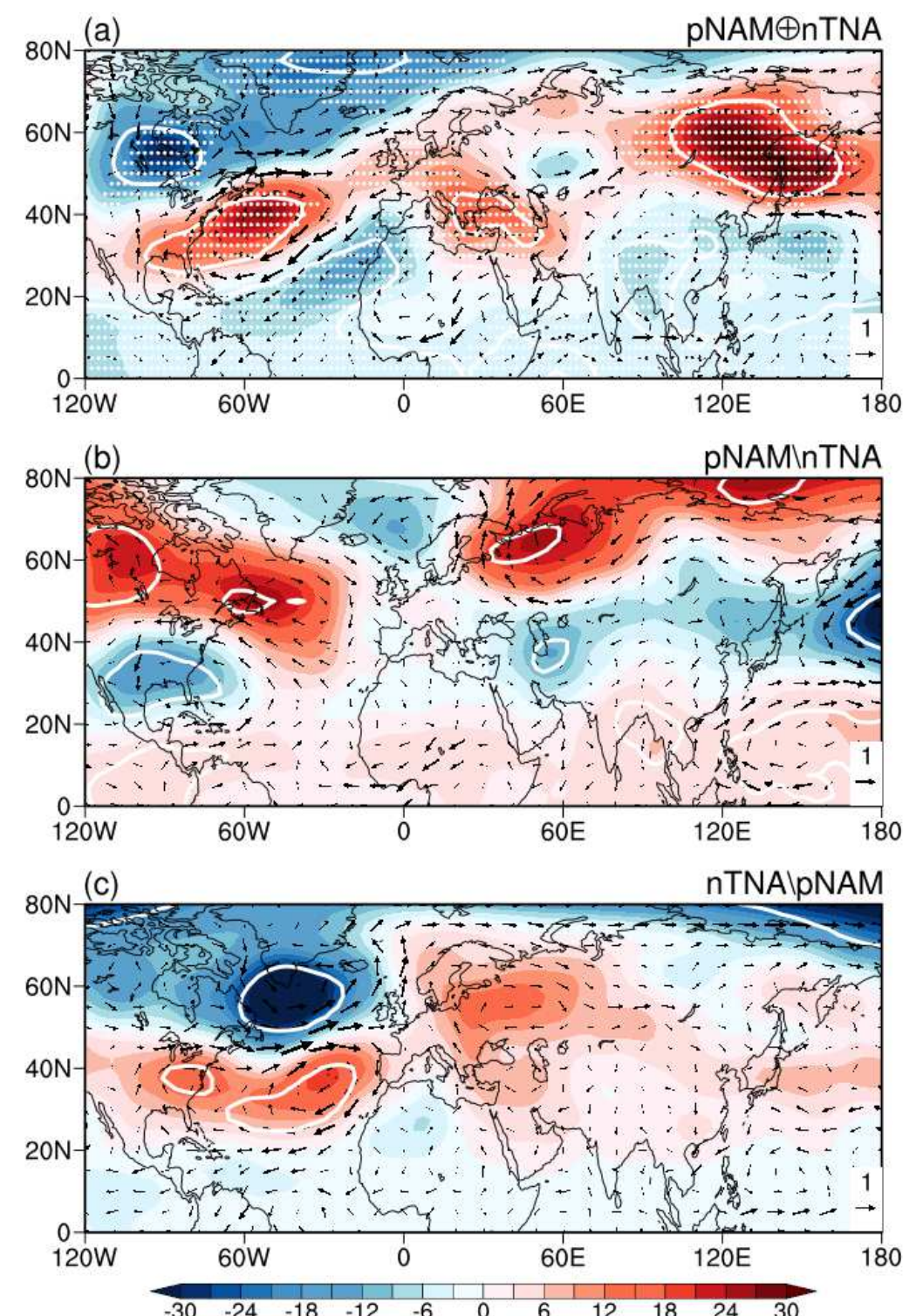

863 Fig. 6. Composite maps of the spring 500-hPa geopotential height (gpm; shaded) and 864 850-hPa winds ( $\mathrm{m} \mathrm{s}^{-1}$; vectors) at for (a) the joint events of preceding winter pNAM 865 and spring nTNA (pNAM $\oplus$ nTNA), (b) single preceding winter pNAM events and (c) 866 single spring nTNA SSTA events. The white dotted areas in (a) indicate the synergistic 867 effect of preceding winter pNAM and spring nTNA SSTA. The white contour lines 868 indicate significant values at the $95 \%$ confidence level based on the Student $t$-test. 

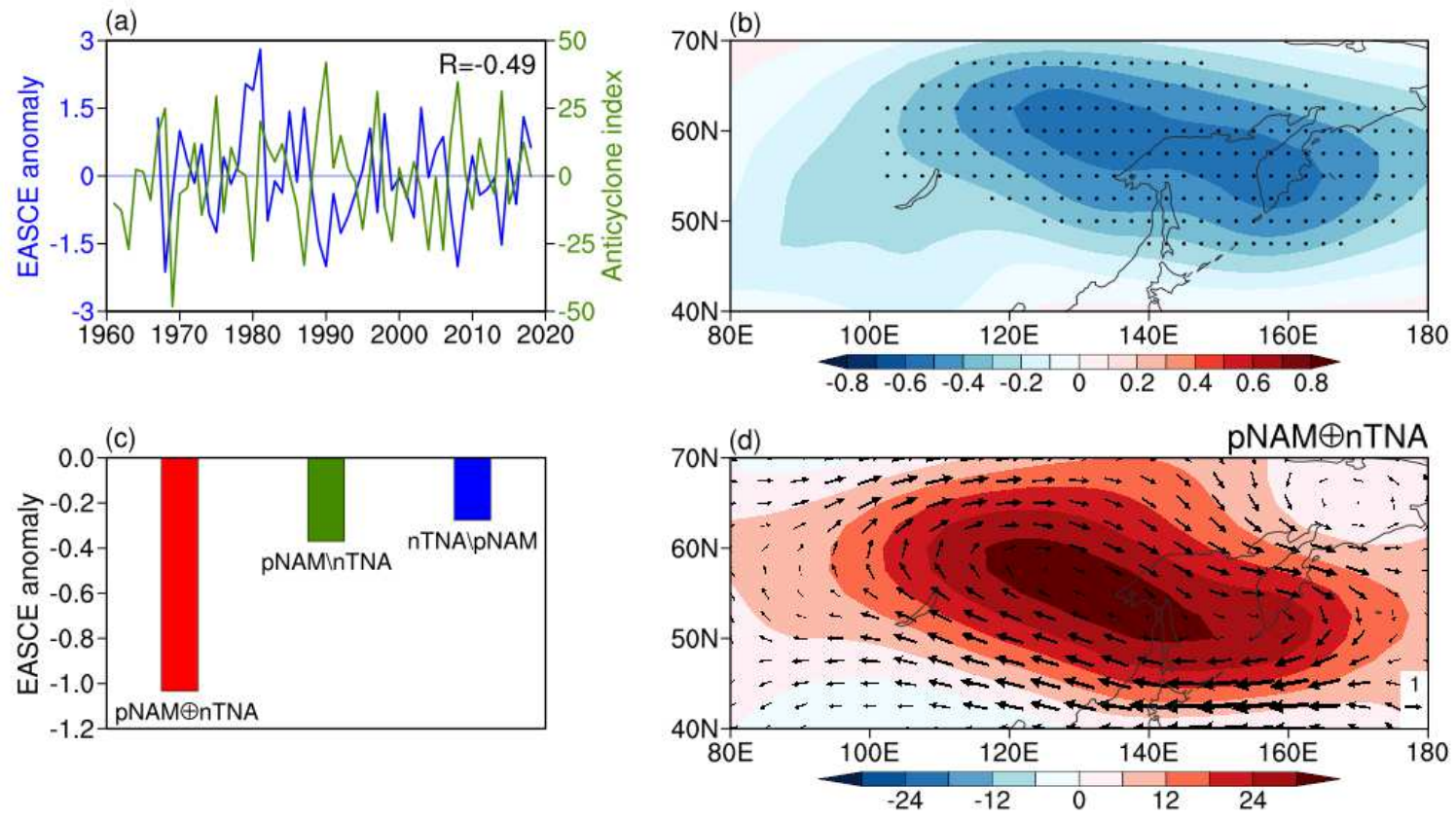

Fig. 7. (a) Time series of the spring EASCE anomalies (blue line, unit: $10^{6} \mathrm{~km}^{2}$ ) and spring MHEA anomalous anticyclone index (green line). (b) Correlation between the geopotential height (gpm) at 500-hPa and EASCE anomalies $\left(10^{6} \mathrm{~km}^{2}\right)$ in spring. Dotted areas indicate the significant values at the $95 \%$ confidence level based on the Student $t$-test. (c) The spring area-averaged EASCE anomalies $\left(10^{6} \mathrm{~km}^{2}\right)$ for the joint events pNAM $\oplus$ nTNA (red), single preceding winter pNAM events (green) and single spring nTNA SSTA events (blue) in spring. (d) The composite map of spring 500-hPa geopotential height (gpm; shaded) and $850-\mathrm{hPa}$ winds $\left(\mathrm{m} \mathrm{s}^{-1}\right.$; vectors) for the joint events pNAM $\oplus$ nTNA. 
(a)

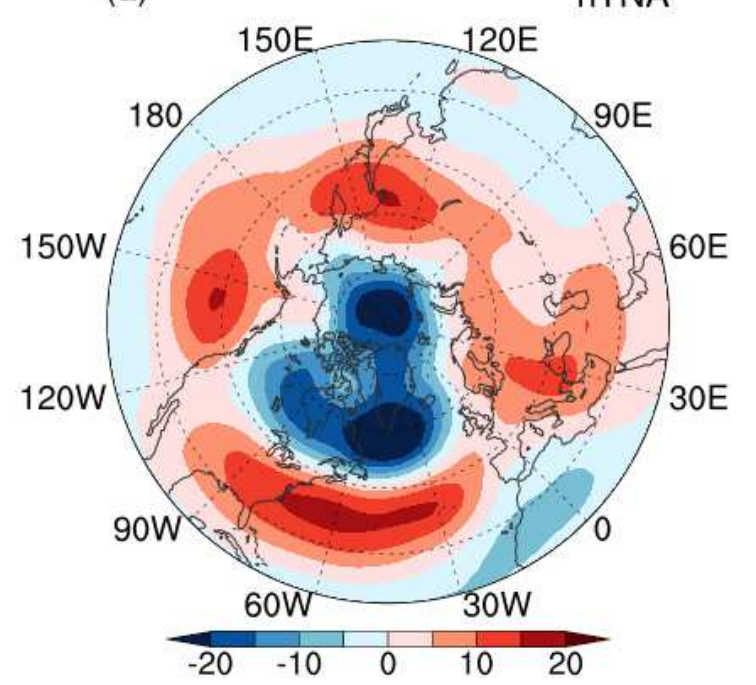

(b)

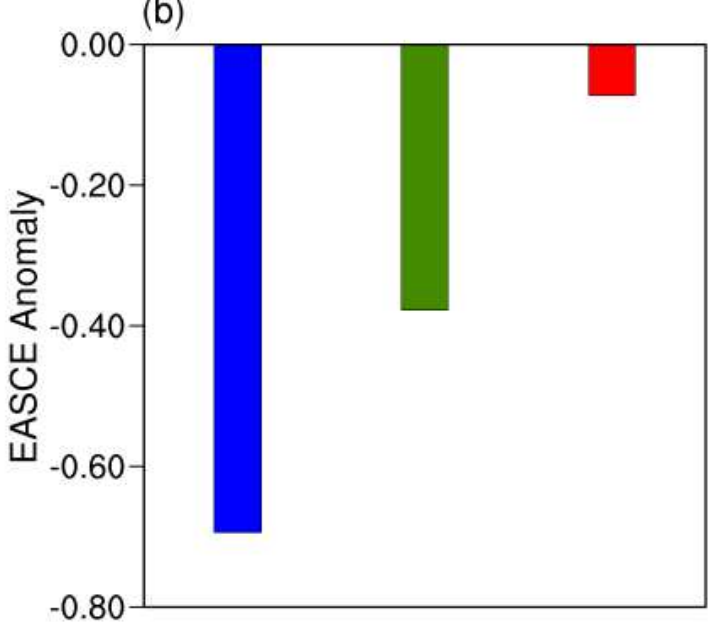
884 Fig. 8. (a) The composite map of spring 500-hPa geopotential height (gmp) for all the
885 spring nTNA SSTA events. (b) The spring EASCE anomalies $\left(10^{6} \mathrm{~km}^{2}\right)$ for different 886 NAM combinations. The red, green and blue bars represent the spring-only pNAM 887 events, preceding winter-only pNAM events and cooccurrence of the spring and 888 preceding winter pNAM respectively. 


\section{Figure 9}

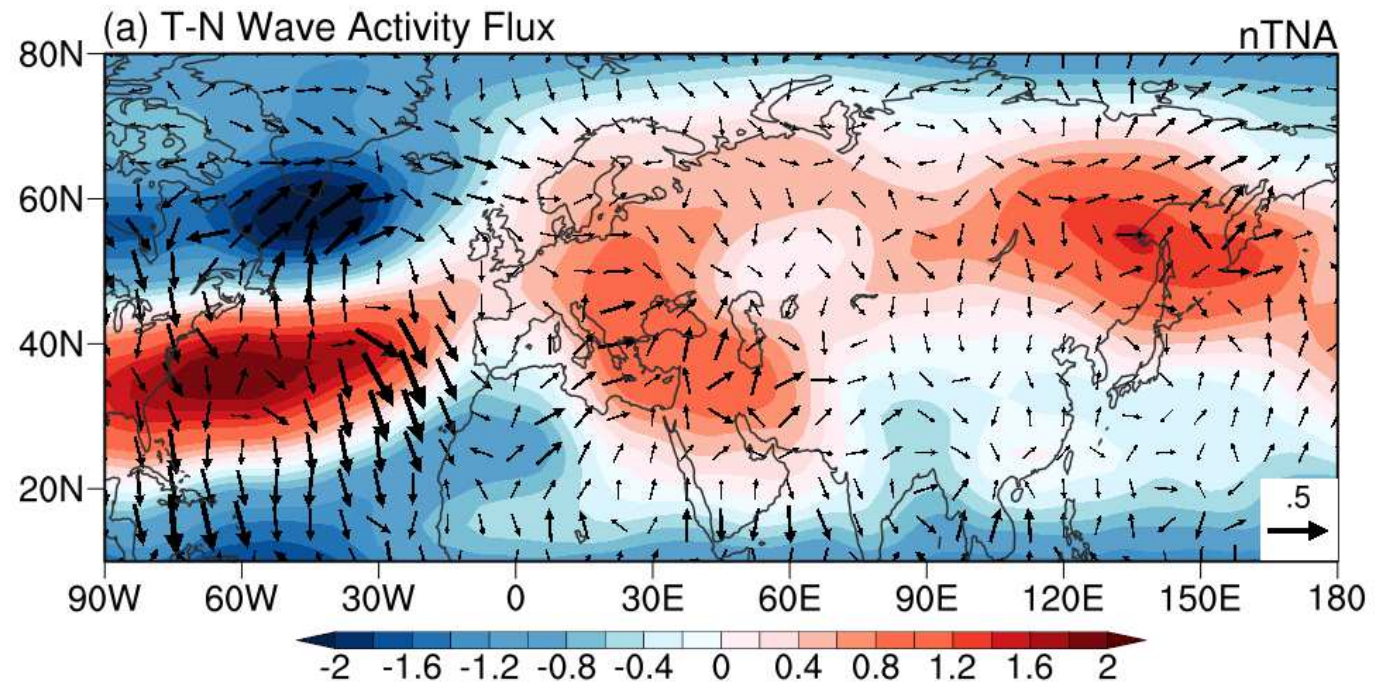

(b) Stationary Rossby Wave Trajectories

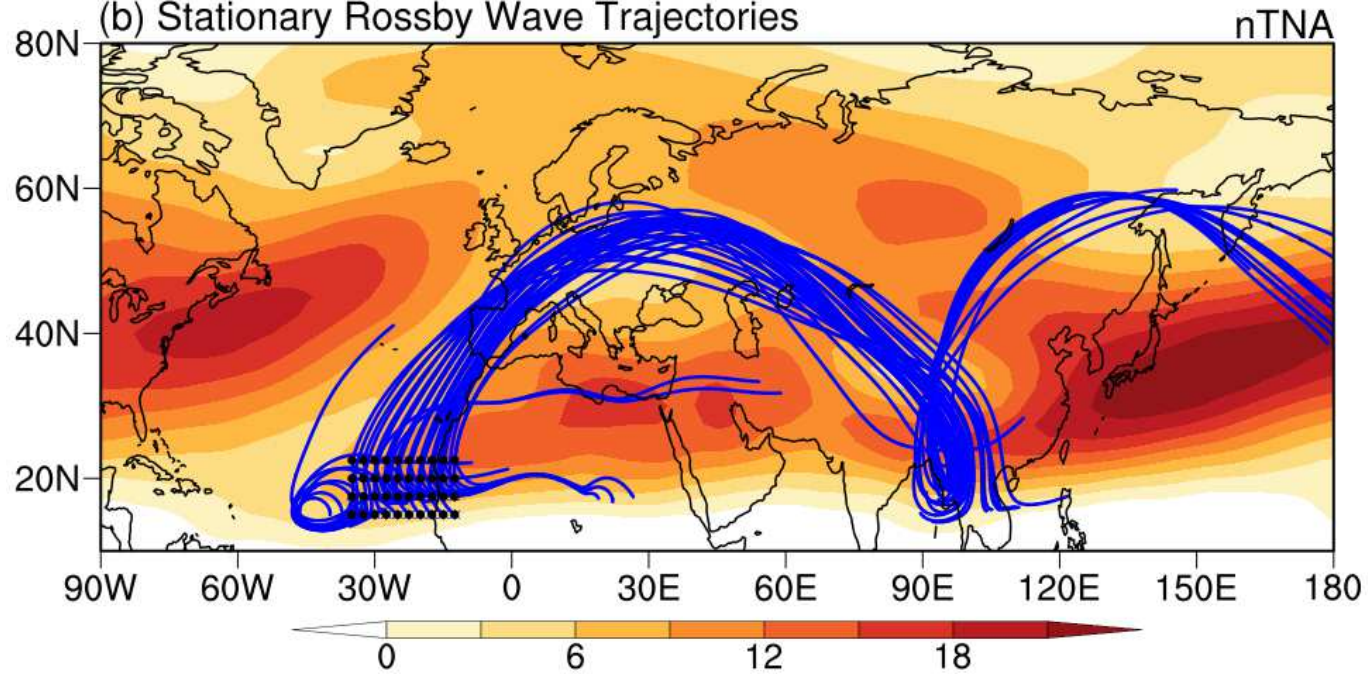

892 Fig. 9. (a) The composite map of spring 500-hPa T-N wave activity flux ( $\mathrm{m}^{2} \mathrm{~s}^{-2}$; vectors) 893 and anomalous QG stream function $\left(\mathrm{m}^{2} \mathrm{~s}^{-1}\right.$; shaded) for all the spring nTNA SSTA 894 events. (b) Spring stationary Rossby wave trajectories in the horizontally nonuniform 895 flow (blue curves) with zonal wavenumber $k=4$ for all the spring nTNA SSTA events. 896 The black dots denote the Rossby wave source. The shaded area is the climatological 897 mean $500-\mathrm{hPa}$ zonal wind $\left(\mathrm{m} \mathrm{s}^{-1}\right)$. The Rossby wave ray tracing is calculated by 898 adopting the approach by Li and Li (2012), Li et al. $(2015 ; 2019 b ; 2021)$ and Zhao et 899 al. (2015). 
$901 \quad$ Figure 10

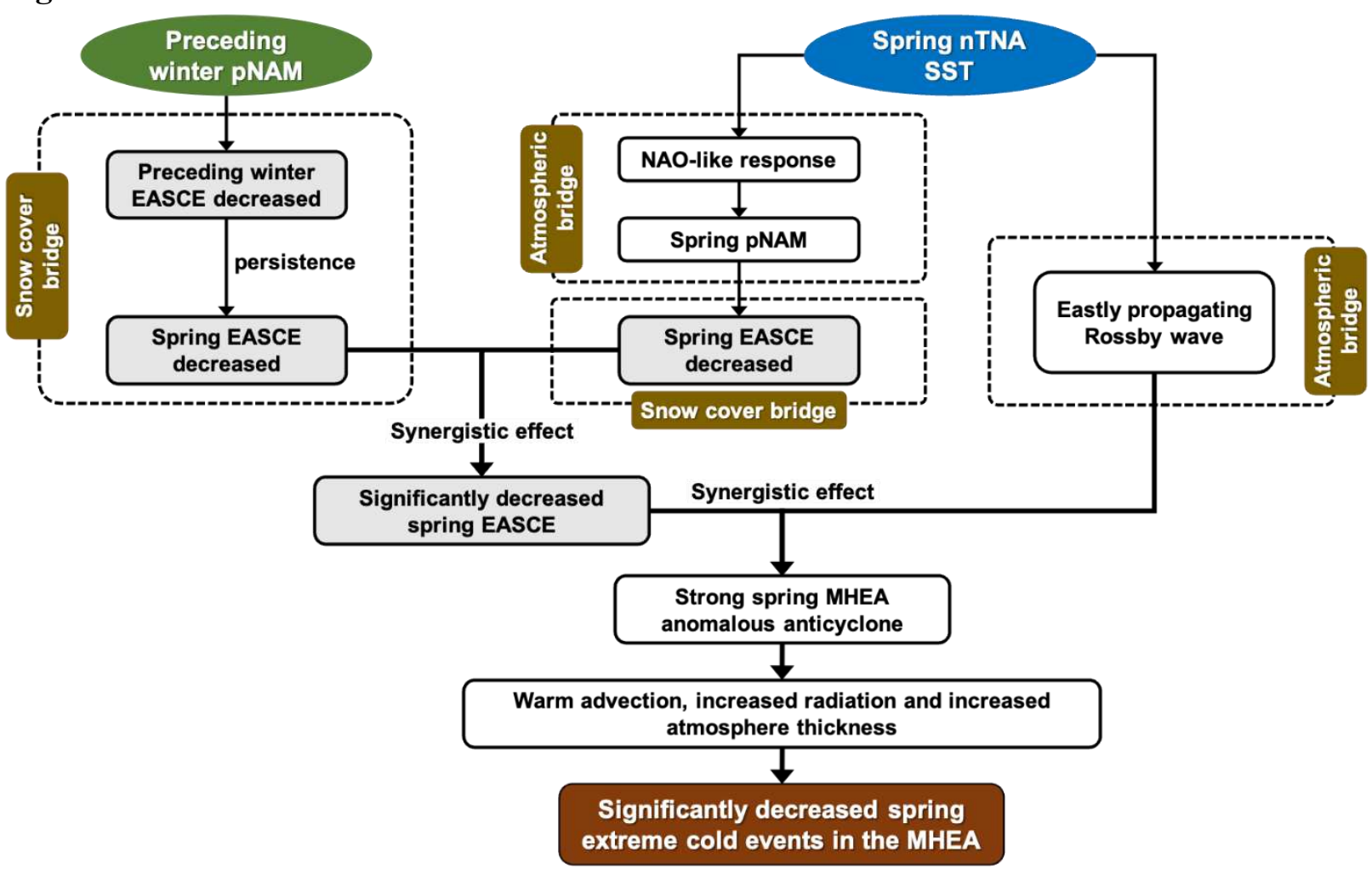

Fig. 10. The schematic diagram showing the synergistic effect of the preceding winter pNAM and spring nTNA SSTA on the spring extreme cold events in the MHEA. 